\title{
Experimental Study of Earthquake Simulator for 3D Cold-Formed Steel Frame Structure
}

\author{
Fatih Alemdar ${ }^{\text {(D) }}$, Fuad Mohammed Ahmed Al-Gaadi a* (D) \\ a Yıldız Technical University, Faculty of Civil Engineering, Department of Civil Engineering, Structural Division, Davutpaşa Campus,34210 \\ Esenler, Istanbul, Turkey. Email: fuadeng5@gmail.com, falemdar@yildiz.edu.tr
}

* Corresponding author: Email: fuadeng5@gmail.com

https://doi.org/10.1590/1679-78256812

\begin{abstract}
This paper aims to perform the experimental test and numerical FE analysis of the cold-formed steel frame structure to provide new proposals to improve the strength, rotation capacity, and seismic energy dissipation in these structures. A 3D full-scale three-story CFS frame structure is experimentally investigated under four sets of input data for $100 \%$ and $50 \%$ scales of Northridge and Kocaeli earthquake acceleration records using the shaking table test. In each test, the frame acceleration and displacement are observed. A FE model is employed to assert the validity of the experimental test. The results indicated that the maximum story drift ratio of the frame ranges from $1.14 \%$ to $3.70 \%$. It is observed that the average similarity ratio of the maximum displacement results between FE analysis and shaking table test is $92 \%$. It is shown that the translational stiffness for the system decrease as the earthquake acceleration records decrease. It is also shown that using the image processing technique in the shaking table test can offer much more acceptable and economical solutions in determining the displacement parameters.
\end{abstract}

\section{Keywords}

Numerical simulation of CFS frame structures, Finite Element seismic analysis, Lightweight steel frame structures, Shaking table experiment.

\section{Graphical abstract}

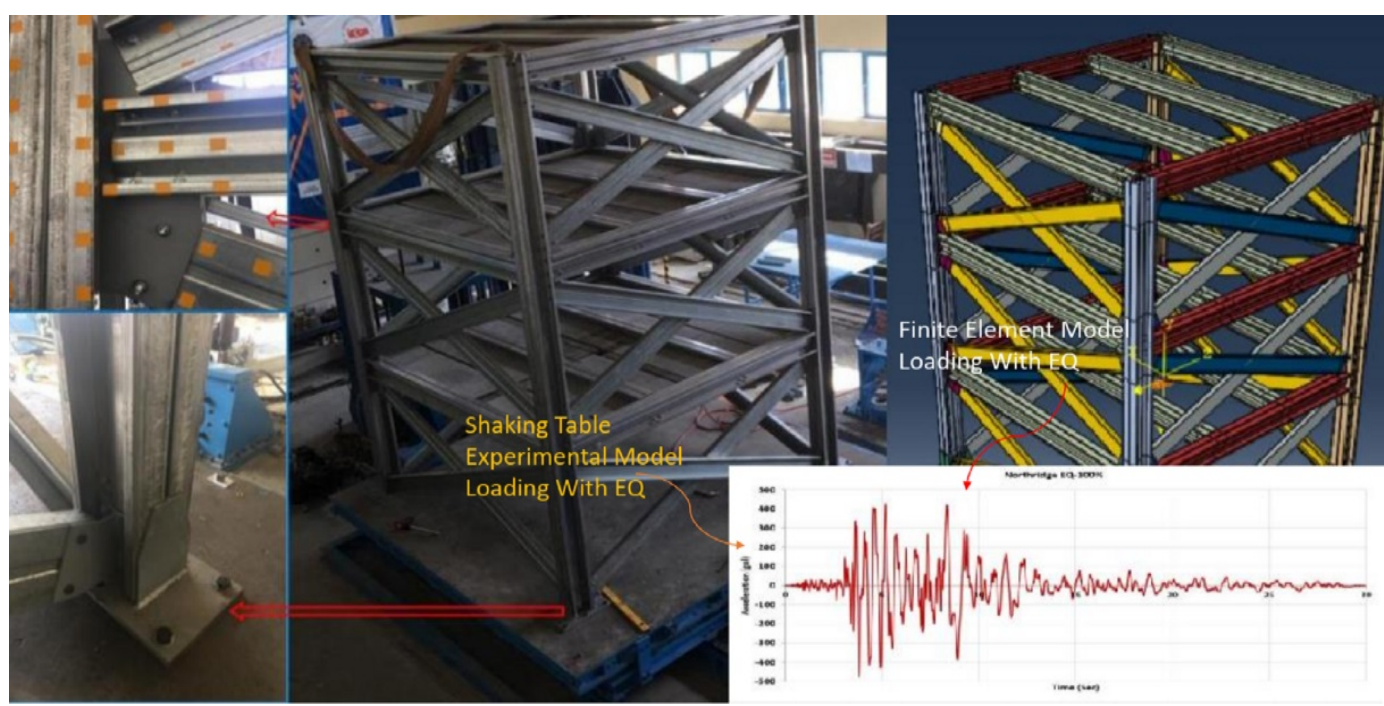




\section{INTRODUCTION AND BACKGROUND}

The braced frame structures consisting of the cold-formed steel (CFS) members are amongst the most common structural systems used for lightweight steel constructions. Cold-formed steel members have been utilized in lightweight steel constructions as fundamental load-bearing elements after the second world war. The diversity of structural elements applications of cold-formed steel (CFS) has increased considerably over the last decade. Structural systems of this type are formed of reduplicated frames connecting light-gauge steel members with sheathing materials such as steel sheets to provide wall-braced components. The cold-formed steel members' characteristics such as the reduction in the costs, an improved versatility of the structure, and being able to create very different houses with a few numbers of structural elements and adequate strength to weight ratio make them able to use in different construction. Moreover, the CFS systems are suitable for any kind of ground, since the requirements of the foundation are not very rigorous for such systems. But the most factors in using a cold-formed steel frame structure are that it provides a lower cost of implementation and maintenance than the other structures, especially when they are built with prefabricated forms.

The controlling failure mode of the CFS structural systems under vertical and gravity loads is generally the local buckling on the compression members due to the width-to-thickness ratio of the members. Consequently, the effective design of these structures requires precise force calculation, the seismic and dynamic behavior of such structures, and logical evaluation of the capability of CFS members. Whilst, the lightweight systems supply the potential to support the requirement for flexible and sustainable constructions, the comprehension concerning their structural behavior in response to excessive events, especially earthquakes and ensuing hazards, stays comparatively not clear.

There are various experiments were investigated (Sabbagh. B. A. et al. 2012; Aly et al. 2018; Bučmys and Daniunas, 2015; Wrzesien et al. 2012) to study the seismic efficiency of the steel moment-resisting frames with gusset plates connections whereby results of the tests were used for validated various modeling methods for estimation of the strength and stiffness of these structures such as detailed FE modeling, equivalent and interior force distributions. In the CFS moment-resistant frame systems, the moments that occurred at the bolted connections can be used to determine the required strength of the columns and beams using the column shear equivalent to the sliding resistance of the bolt group and the connecting bearing element of the column shear relating to the design story drift.

The seismic behavior of CFS frame structures has been investigated by many research (Schafer et al. 2016; Dubina. 2008; Di Lorenzo and Martino. 2019; Fiorino, luorio and Landolfo. 2014; Ye, Mojtabaei, Hajirasouliha and Pilakoutas. 2019; Pouladi et al. 2019). The behavior of the lateral load-resisting shear wall systems was the main focus of most of these studies. With moment-resistant CFS frame structures, dependency on the shear wall panels can be decreased, and thus more flexibility can be provided for space planning and future improvements. On the other side, many studies were shown that the seismic efficiency and energy dissipation of the structures during strong earthquakes may be improved when moment-resistant CFS frames use instead of shear wall systems.

In the concentrically-braced frames, the brace elements are subject to sequence tension and compression loads when the structure is exposed to seismic loading. The complicated asymmetric responses for bracing members were observed in many investigations of the cyclic behavior for concentrically-braced frame steel structures (Amin et al. 2019; McCrum et al. 2018; Moushtakim, B. 2020; Bosco et al. 2013; Faytarouni et al. 2019; Tremblay. 2002; Feng and Young. 2015; Nip et al. 2013). Many of these studies are dependent on comparatively static cyclic experimentation performed for various ranges of the member slenderness within preset data of displacement, with relatively limited experiments for the actual dynamic loads.

The dynamic finite element analysis method is the most developed technology that can be used to simulate the seismic behavior of systems such as diagonal braced-frame systems. Surely, the dynamic finite element analysis could be used to compare and check the validity of the experimental results of shaking table tests. In reality, seismic recordings are collected and a wide amount of data is generated only for particular applications. In this concept, the use of non-linear dynamic analysis for earthquake estimation has greatly expanded during recent years. Opposite to the other analysis technologies, the major factors for this attractive methodology are its relative simplicity in terms of modeling, analytical specifications, giving results close somewhat to the results of laboratory experiments and the ability to understand the results (Krawinkler, Seneviratna. 1998).

(Pouladi et al. 2019), in their experimental study, investigated the critical failure modes of a cold-formed steel portal frame comprised a single channel section for the columns and rafter's eaves connections. The results revealed that the critical mode of failure is a combination of torsion of the eaves joints and the shear failure of screws. It was also found that there was slipping in the bolts observed at the ultimate load instead of engagement. Finally, they came up with some important conclusions in eaves joints such as the ability of screws to provide in practice to prevent slipping of the joints during frame erection and contribute to the connection stiffness. 
Vahdani et al. (2017) investigated the seismic vulnerability of steel-resisting moment frames based on plasticity development in structural components to identify the location of plastic hinges at the collapse state. The results indicated that the maximum inter-story drift ratio of the frame ranges from $1.5 \%$ to $10 \%$ at the collapse state. Also, the pushover analysis with the first mode load pattern identifies more plastic hinges for the steel frames compared to with uniform load pattern. The results also were shown that the triangular linear patterns give similar results to the first mode pattern for the regular steel frames.

Avcl and Alemdar. (2019) studied a 1:4 scaled three-story steel frame structure constructed on the shaking table platform. The experimental and analytical FE models were performed. The model was loaded by a paving stone of 750 $\mathrm{kg}$ as a static loading for each floor. The structure was tested under Northridge and Kocaeli earthquake acceleration record data. The experimental and analytical results indicate that the second-order effects are appeared as the acceleration amplitude of the earthquake increased and the results obtained from the shaking table test verified the results of the FE model analysis carried out by the ABAQUS software.

Goggins et al. (2017), based on the serviceability, ultimate and collapse limit states, investigated experimentally the effect of the gusset plate and brace properties on the concentrically braced frame response. Twelve experiments were examined on full-scale single-story frames. All test frames were exposed to uniaxial seismic excitation scaled to represent low, medium, and high-level excitation. The experimental results showed that the brace-gusset plate continued elastic during low-level seismic excitation, brace buckling and yielding observed in all medium-level excitation tests, while brace fracture is developed in all high-level excitation tests. It was shown that there is no fracture occurred in the gusset plate connections regardless of whether they are designed according to the balanced or the conventional method. It was also shown that the plastic strain distributions are more uniform and led to higher brace ductility capacity when the gusset plates are designed using the balanced design method than the conventional method. Furthermore, using the bolts instead of welds in the gusset plate connections demonstrate satisfactorily and provide more efficient construction solutions.

Campiche, A. (2020) based on finite element numerical analysis, explained the seismic behavior of CFS strap braced frames that are subjected to high-intensity earthquake acceleration records. The results indicate that the ratio of fundamental periods of vibration between the experimental and numerical analysis results ranges from 0.80 to 2.08 . The experimental and numerical results have been shown that the FE models of the test frames are able to capture peakinter story drift ratio for low inputs of the earthquake accelerations, whereas they did not demonstrate good prediction for higher inputs due to the deformability source resulting from the rocking phenomenon observed experimentally.

Firouzianhaij et al. (2021) conducted experimental shaking table tests on standard steel storage rack systems to study the dynamic inelastic response, seismic characteristics, and the damping of the rack system under a realistic strong ground motion. The results indicate that, under actual time-domain conditions, the lateral displacement, base shear, and the accelerations of the rack system are more than when the time-domain is scaled down. The results of tests were shown that a significant rise in the damping ratio versus the maximum lateral displacement of the system was observed. It was also noticed that the soft story mechanism at the first story of the rack system is greater than that of the second story and this effect increase more at higher intensity earthquakes.

From the literature, it is understood that realistic experimental investigations of the seismic response of the coldformed steel structures, the overall capacity, the structure durability, the energy dissipating zones and the likely plastic interactions between the members are severely limited for the CFS frame structures. Moreover, most of the previous studies focused on the linear behavior of the frame structures with standard cold-formed steel profiles which were performed based on experimental tests of non-full scaled frame structures due to the expensive cost of the experimental shaking table tests. This study aims to address these issues experimentally for a full-scaled CFS frame structure with profiles designed especially. A finite element model closed to the real structure was carried out to evaluate the validity of the experimental test. The structure was constructed on the shaking table platform and several stone cubes were applied on wooden plates on each floor as a static load. Experiments are performed using four sets of earthquake acceleration records; $50 \%$ scale and $100 \%$ scale of Northridge and Kocaeli earthquake records as input data for the test. For each input data, the dynamic parameters and seismic behaviour of the structure were observed during the experimental test. Based on the results, conclusions regarding the nonlinear seismic behaviour of the cold-formed steel frame structure the displacement responses were drawn. The results of this study may be used to calibrate finite element models as well as seismic provisions for the cold-formed steel frame design. 


\section{METHOD AND MATERIALS}

\subsection{Geometric and mechanical properties of steel frame}

A 3D full-scale three-story of cold-formed steel frame structure was constructed on the shaking table platform in the laboratory as shown in Figure 1 . The dimensions of the frame are $3 \mathrm{~m} \times 3 \mathrm{~m}$ in the plan and the frame is divided into three-story each of them being $1.5 \mathrm{~m}$ in height. Double sigma section S200X80X2 mm back-to-back was used in the columns and beams and channel section C180X60X2 mm was used in the braces as shown in Figure 2. A 480x260x20 mm plate was used in the base to connect the structure with the test platform. The beam-column and braces joints were connected with a $625 \times 360 \times 7 \mathrm{~mm}$ gusset plate in the Z-direction and with a $576 \times 176 \times 7 \mathrm{~mm}$ gusset plate in the x-direction. Two middle secondary beams were used on each floor to support the vertical loads and to avoid the expected buckling occurring in the beams in the Z-direction. Secondary beams are connected to the main beams with a $200 \times 130 \times 7 \mathrm{~mm}$ plate. All members were connected with connection gusset plates using $12 \mathrm{M} 12-8.8$ bolts.


Figure 1: Experimental specimen of cold-formed steel frame structure

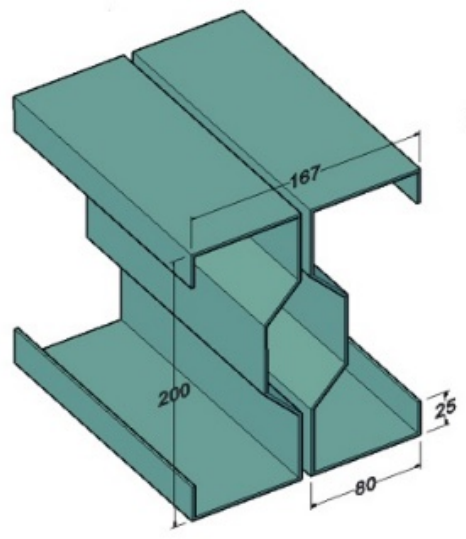

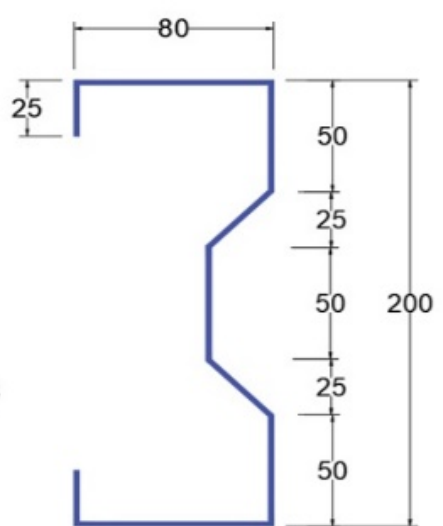

(a)
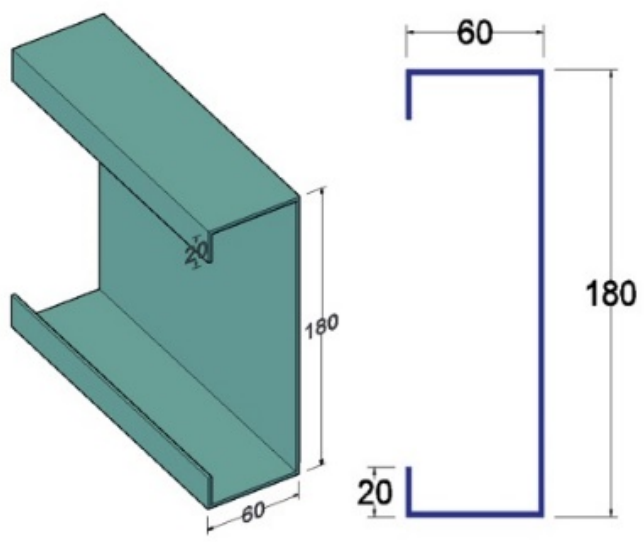

(b)

Figure 2: Section details (a) Column and beam section (b) Brace section (dimensions in $\mathrm{mm}$ ) 


\subsection{Mechanical properties of steel frame}

The elasticity modulus of $210 \mathrm{GPa}$ and Poisson ratio 0.3 was used as material properties for the components of the cold-formed steel structure. The ultimate and yield stress of the steel is $380 \mathrm{MPa}$ and $270 \mathrm{MPa}$ respectively. The stressstrain relationship of the cold-formed steel is defined in the finite element model to allow the nonlinear solution during the analysis as illustrated in Figure 3.

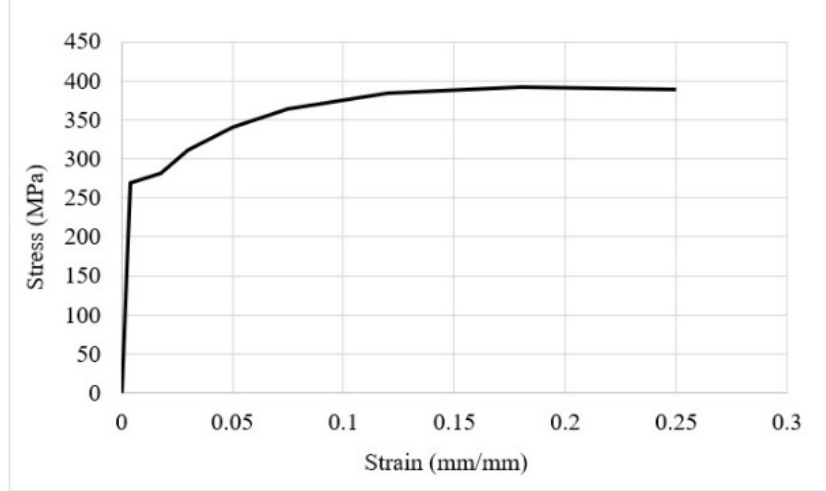

Figure 3: The stress-strain relationship of cold-formed steel

\subsection{Experimental test}

A full-scale 3D cold-formed steel frame structure was experimentally tested in the civil engineering laboratory at Yildiz Technical University. The structure was constructed on the platform of the shaking table and loaded by several stone cubes applied on wooden plates on each floor as mentioned before. Many reference points were painted on every floor of the structure to be used to extract the experimental results. The test was performed using four sets of earthquake acceleration records; $50 \%$ scale and $100 \%$ scale of Northridge and Kocaeli earthquake records as input data of shaking table test. The movements of the structure during the experimental test have been recorded by a camera was placed in front of the structure. The recorded videos were converted to many image frames. After that, the Digital Image Correlation (DIC) technique using the reading data program which carried out by Avcl and Alemdar. (2019), was used to read the experimental displacement results in the points marked on the structure as shown in Figure 4.

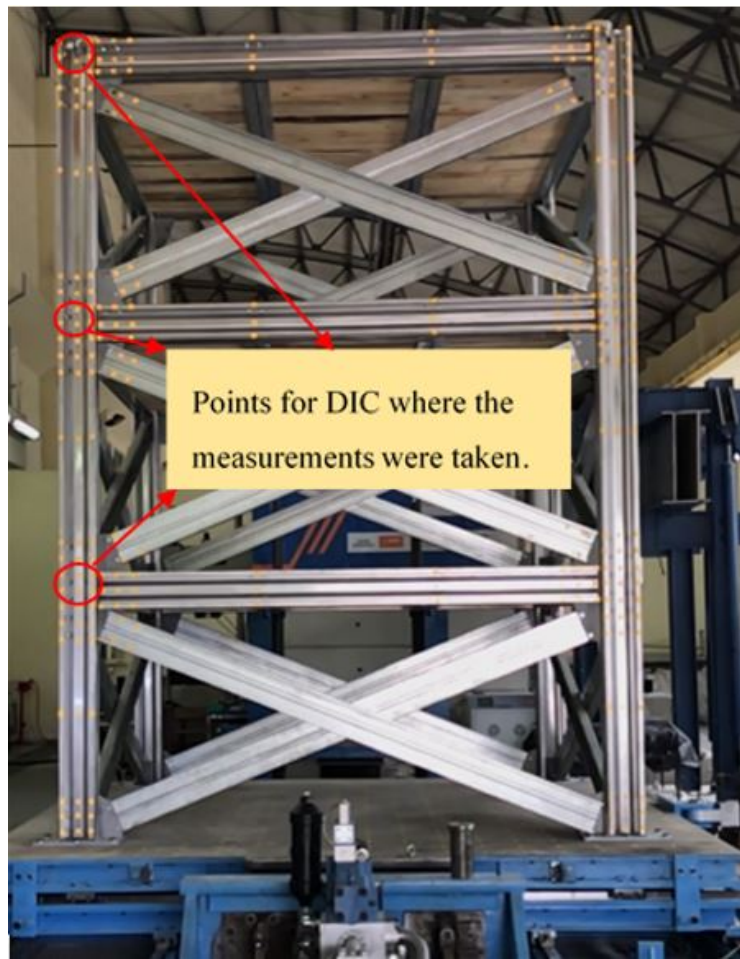

Figure 4: Points where the experimental results were taken 


\section{CYCLIC BEHAVIOR OF COLD-FORMED STEEL FRAME}

Before studying the seismic behavior of the cold-formed braced steel frame, A numerical modeling of the 3D coldformed steel frame was performed with a different type of assembling the connections using the finite element software ABAQUS to investigate the behavior of the structure under cyclic loading to show the affecting of the simulation mechanism in FE model for the bolted connection either as a full tie constraint or as circular connected areas represent the bolts shank on the results of the other members in the model. The cyclic analysis for the structure was performed to select the best interaction method between the members in the joints for the FE model which represents the actual behavior of bolted connections in the proposed 3D frame model that will be studied experimentally and analytically under the earthquake loading effects.

A detailed two FE models were generated in ABAQUS, (Alemdar, Geleta and Algaadi.2021), to simulate the cyclic behavior of the cold-formed steel frame structures in a different case of the connection simulation mechanism as shown in Figure 5. The first model was generated by simulating the contact surfaces in the connection regions as a full constraint behavior while the second model was generated by simulating the contact surface between the bolts, gusset plate, and beam-column connections as an actual area of the bolts connected without friction. In the simulated models, the influence of geometric imperfections, non-linearity, and the effects of contact mechanisms was taken into account in the analysis.

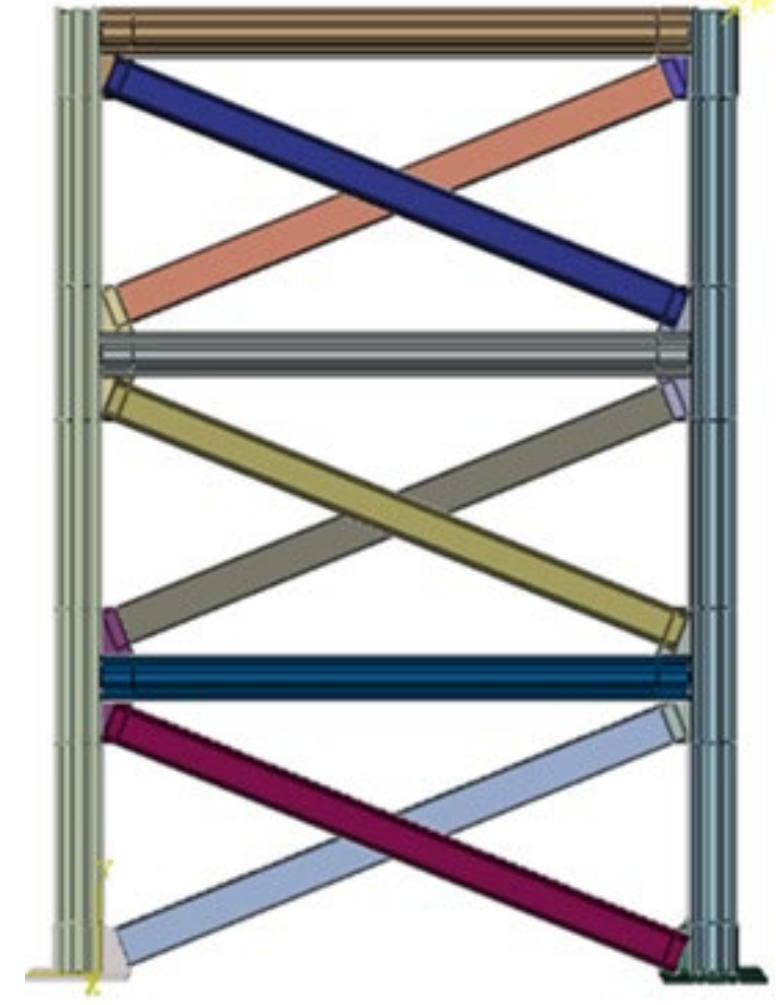

(a)

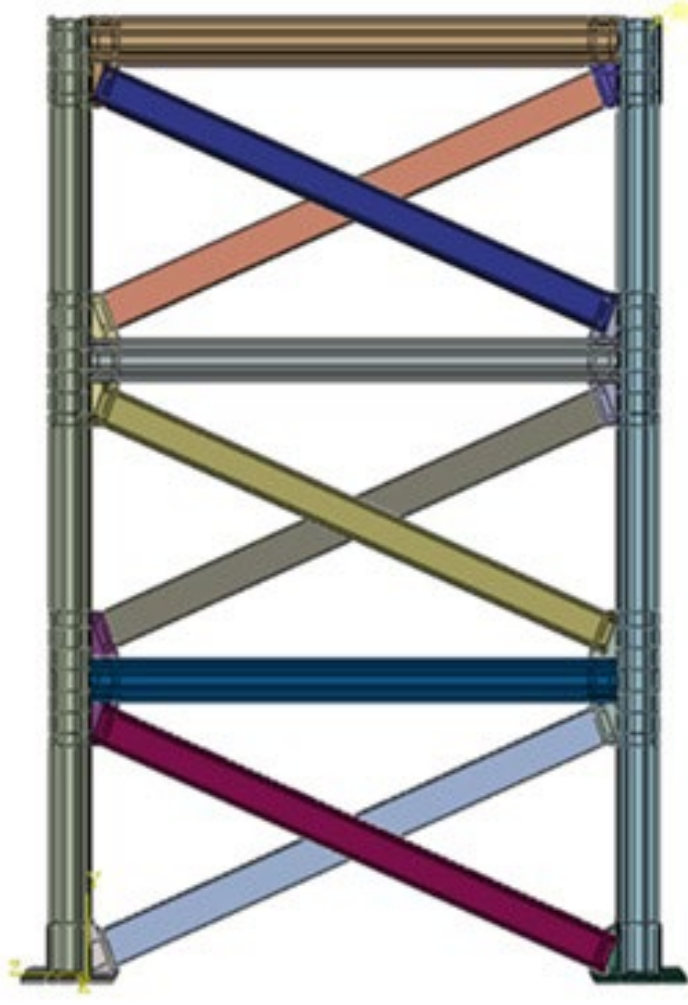

(b)

Figure 5: Finite element models: (a) model I (b) model II

The connections between the beams and columns were designed using gusset plates by a series of bolts distributed along the connection region. In ABAQUS, the bolt groups have been simulated in the FE models in two methods that were used to simulate the real behavior of bolted connection at the column-beam joints. In the first method, the diameter of each bolt was given a physical radius ( $r$ ) equivalent to half the bolt-shank (Pouladi et al. 2019; Amin et I. 2019). Every point of fixing was displaced and rotated as the average of the surrounding nodes (Figure 6.b). With this simulation approach, stress concentrations around the bolt location in the FE model may be more intense. The second method is by using surface-to-surface tie constraint contacts to simulate the properties of contact between the beams, columns, and gusset plates (Figure 6.a). This approach may make the analysis converge easier.

In the finite element model, the members composed of the model have been simulated as $3 \mathrm{~d}$ elements. The C3D8 field-variable-dependent conductivity elements with eight nodes per element and three degrees of freedom per node 
were chosen. A $10 \mathrm{mmx10} \mathrm{mm} \mathrm{fine} \mathrm{mesh} \mathrm{was} \mathrm{adopted} \mathrm{near} \mathrm{the} \mathrm{connection} \mathrm{and} \mathrm{a} \mathrm{coarse} \mathrm{mesh} \mathrm{was} \mathrm{adopted} \mathrm{at} \mathrm{the}$ unconnected place by dividing the members into $100 \mathrm{~mm}$ elements. The finite element mesh of the frame is shown in Figure 7. A cyclic loading protocol from FEMA 315 was used in the FE model to model the cyclic behavior of the coldformed steel frame, The gravity loads; self-weight, are applied to the model during the cyclic loading. Cyclic loading was applied as a static load at the top of the right column as shown in Figure 8.

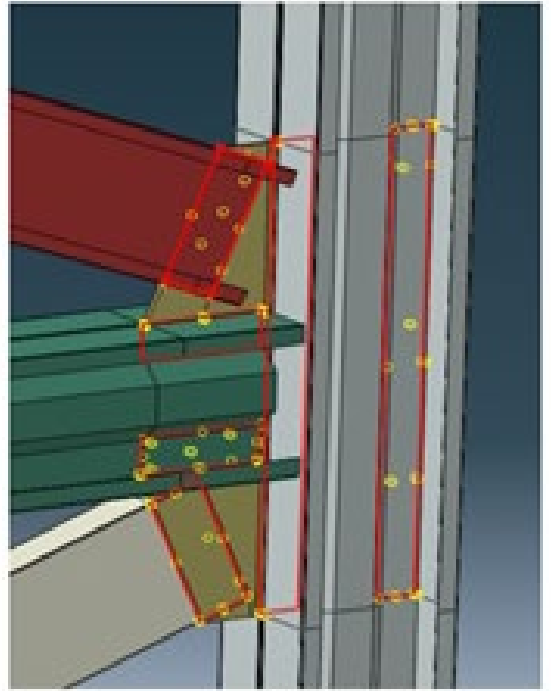

(a)

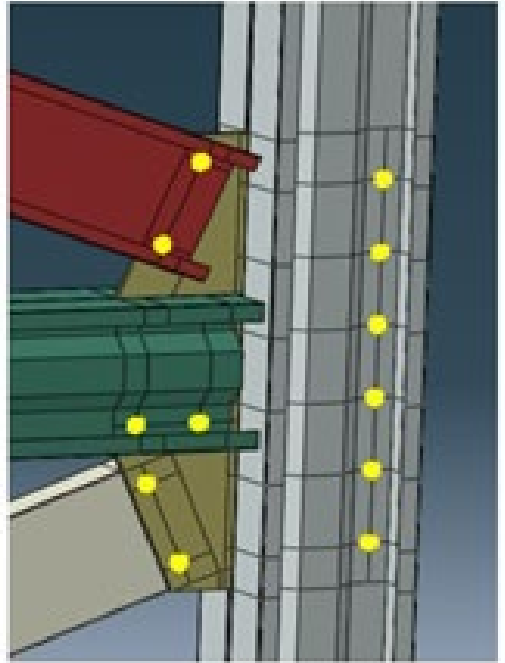

(b)

Figure 6: FE simulation of the connections and constraint types; (a) Model I and (b) Model II

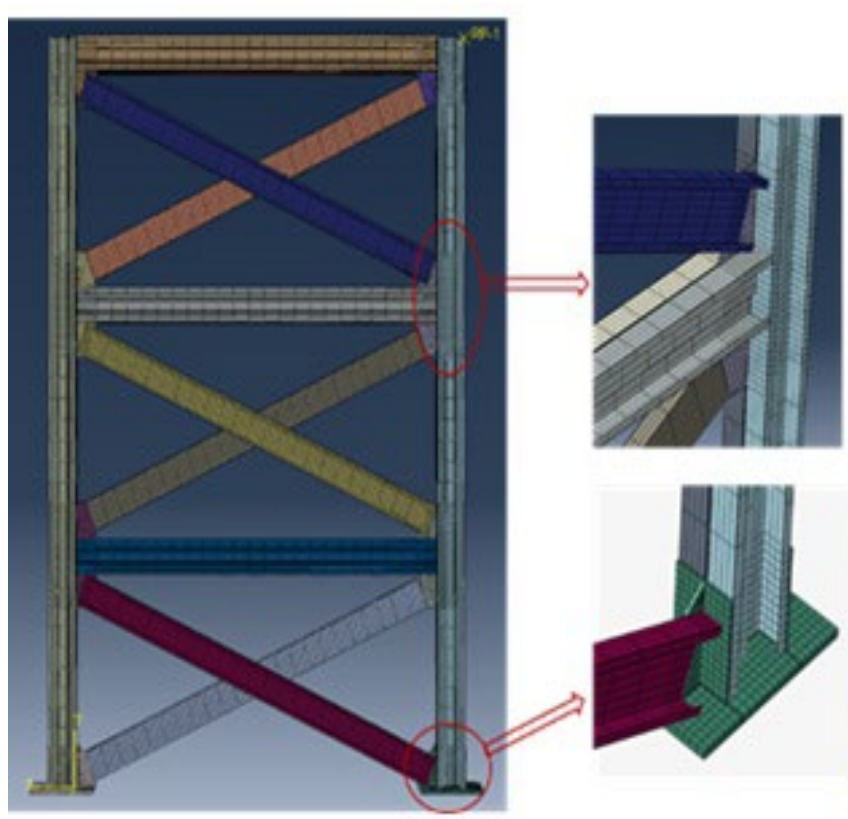

(a)

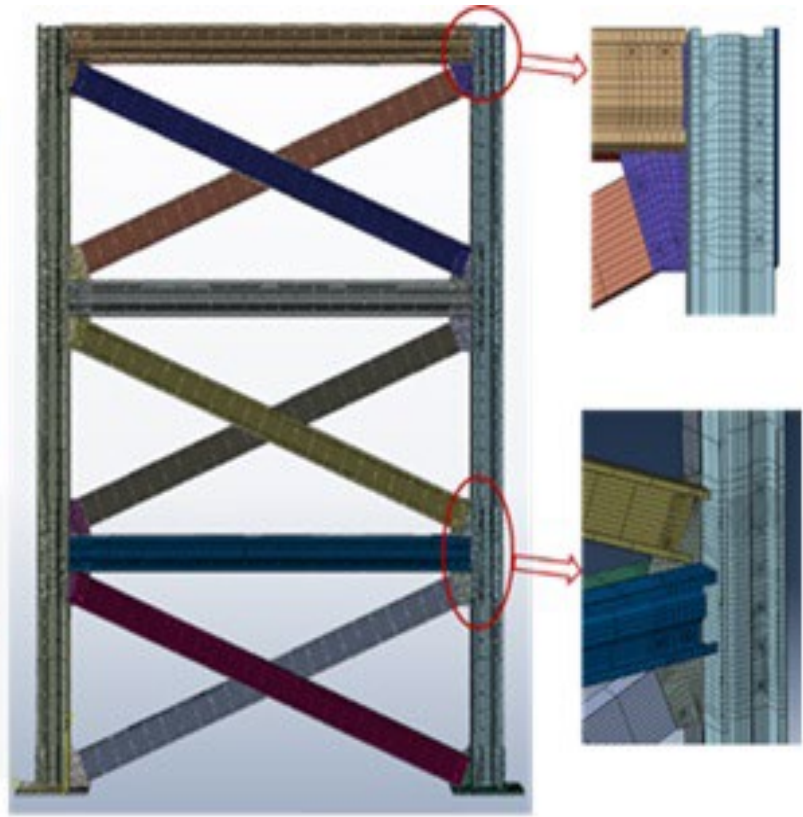

(b)

Figure 7: Mesh of the FE models :(a) model I (b) model II

\subsection{Results of FE cyclic analysis}

The displacement response, cyclic behavior, brace stress, axial forces, and stiffness were investigated during the cyclic analysis. The results showed that Model I failed at the connections and the bottom part of the columns' screws and crushed along the edges as shown in Figure 9. The braces failed firstly at the region of the connection area which leads to maximum stress as a result of the sudden transfer of load. Whereas the failure and maximum stresses on model 
II were observed at the connected circular areas that represent the bolts at the connection and this failure leads to local buckling at the edges of braces.

During the cyclic analysis, numerical results showed symmetrical and stable hysterics behavior of the CFS structure when the connection surfaces were simulated as bolts in ABAQUS. It was also observed that the cold-formed steel frames are much stiffer when contact surfaces between the members simulate as a full constraint in ABAQUS. In contrast, when the area of the bolts is simulated in the connections, the greater closed area of cyclic loops in the CFS braced frames results in significantly higher energy dissipation.

The maximum tensile force on the brace reached $94.5 \mathrm{kN}$ and $89.2 \mathrm{kN}$ in model I and model II respectively. That means the tensile force on the brace members increased by $5.94 \%$ when the connections were simulated mathematically as full tie constraint surfaces instead of real bolted connections. The results have shown that the maximum displacement increased by $5.36 \%, 8.73 \%$ and $10.44 \%$ in the first, second and third floors respectively when the connections are simulated as full constraint surfaces in the finite element model as illustrated in Table 1. In general, the FE analysis results showed that the model displaced more when the mechanism of the bolted connections are simulated in ABAQUS as a full tie constraint (Figure 10).

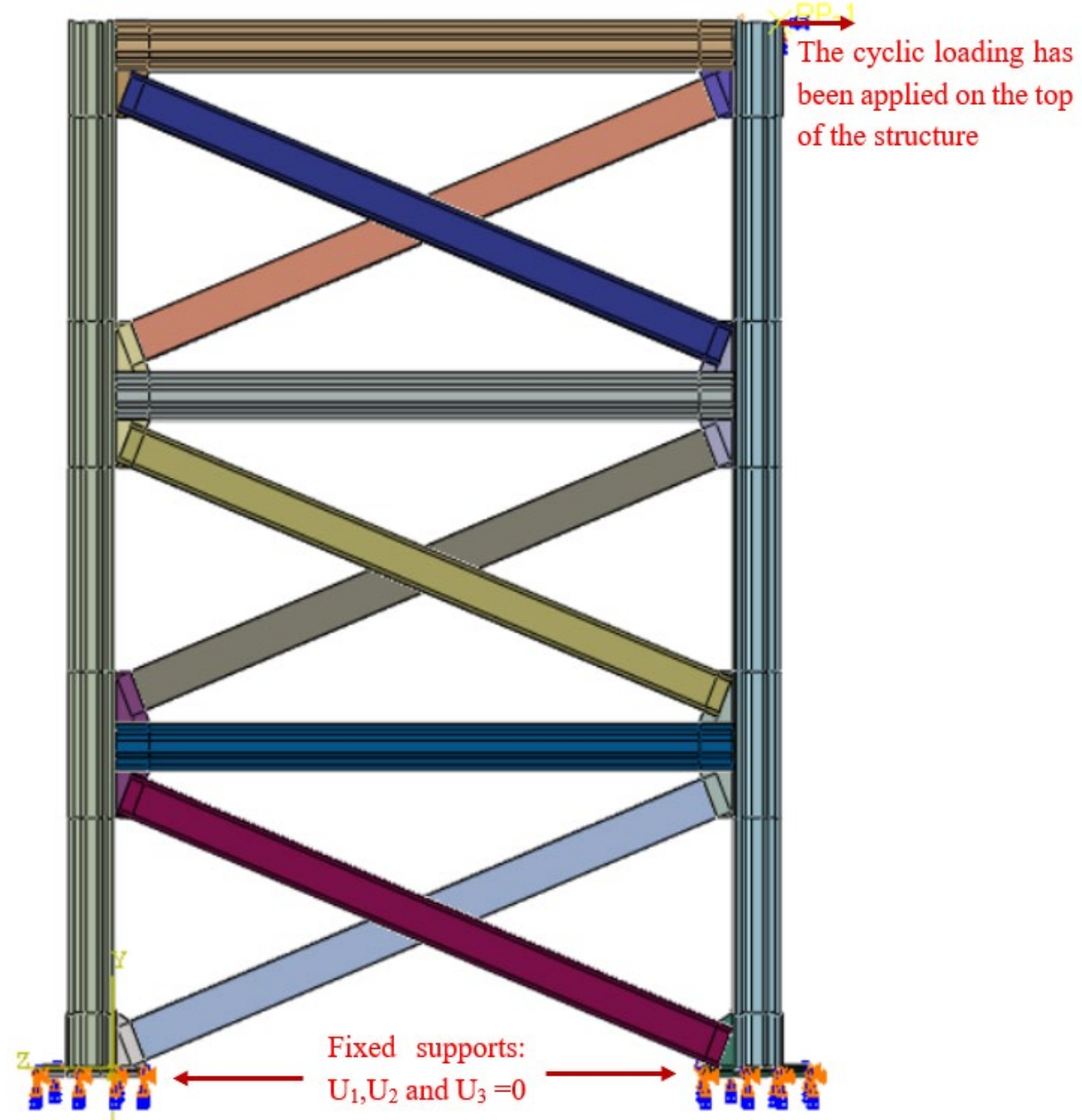

Figure 8: Boundary conditions and FEMA 315 cyclic loading protocols used in the FE cyclic analysis

The result of cyclic FE analysis was obtained from the simulation of the two cases for the model. Figures 11,12 and 13 compare the shear force-displacement response of the cold-formed steel frames under the cyclic loading. The results have shown that when the connection is simulated as a tie constraint by using the surface-to-surface contact pair constrains, the stiffness and the energy dissipation capacity of the model increase. On the other hand, when the connections in the model are simulated by using the bolt area, more failure at the connection regions is observed and the stress concentrates mostly around the bolt shank. Then this connection simulation mechanism leads to the transfer of small stress to the braces due to the small stiffness joints which connected the braces to the beam-column sections as shown in Figure 9.b. 
Table 1 Maximum displacement obtained from FE Analysis under cyclic loading $(\mathrm{cm})$

\begin{tabular}{cccc}
\hline & & Maximum Displacement & \\
\hline & First Floor & Second floor & Third Floor \\
Model I & 6.48 & 16.93 & 22.64 \\
Model II & 6.15 & 15.57 & 20.50 \\
\hline
\end{tabular}

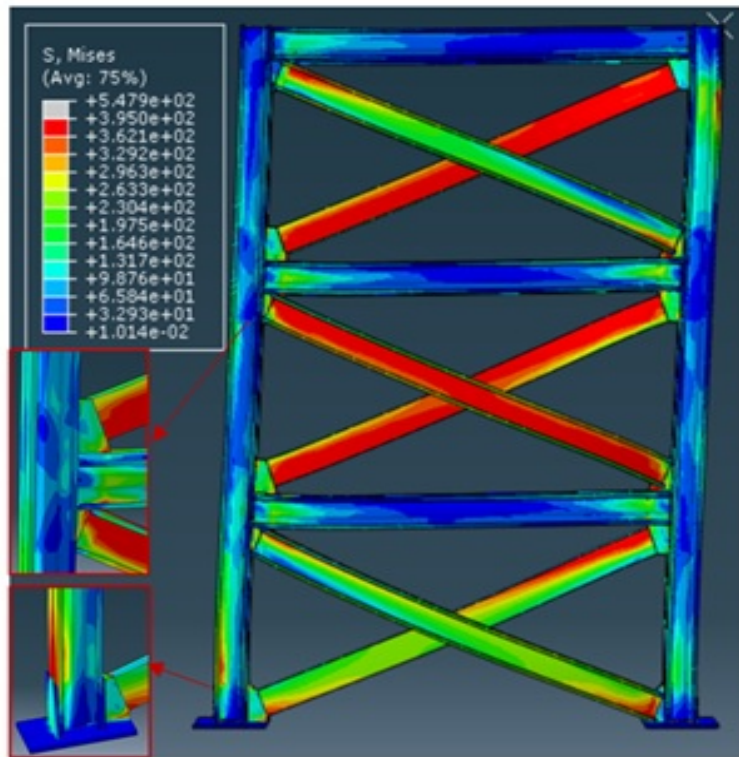

(a)

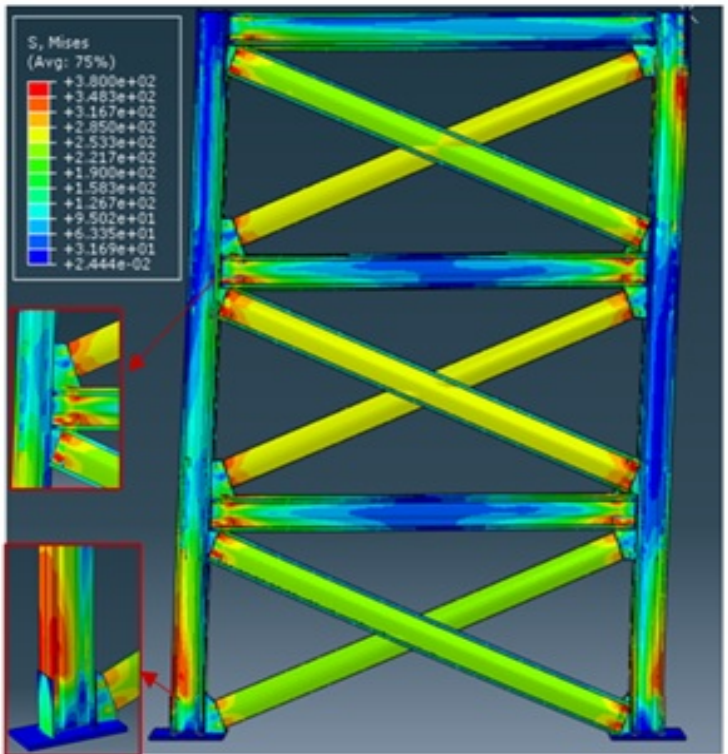

(b)

Figure 9: Von mises stress distribution obtained by cyclic loading analysis; (a) Model I (b) Model II

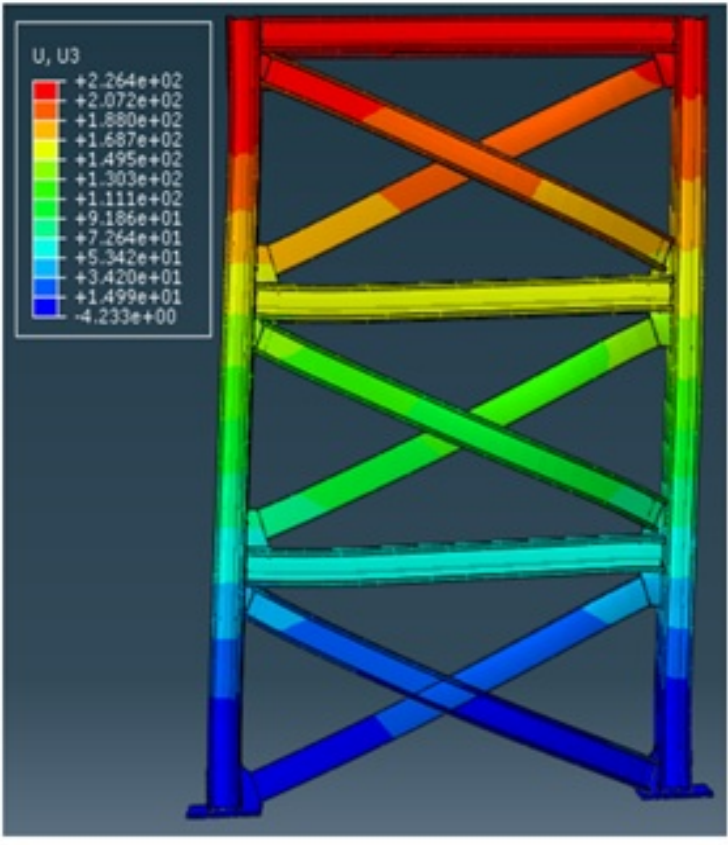

(a)

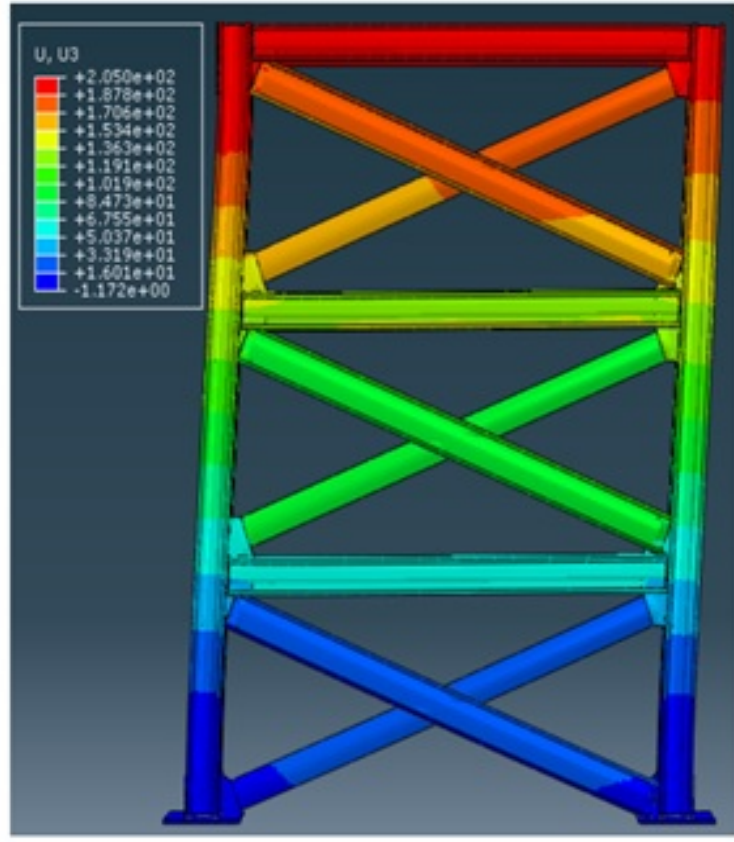

(b)

Figure 10: Displacement response of the frame structure; (a) Model I (b) Model II 


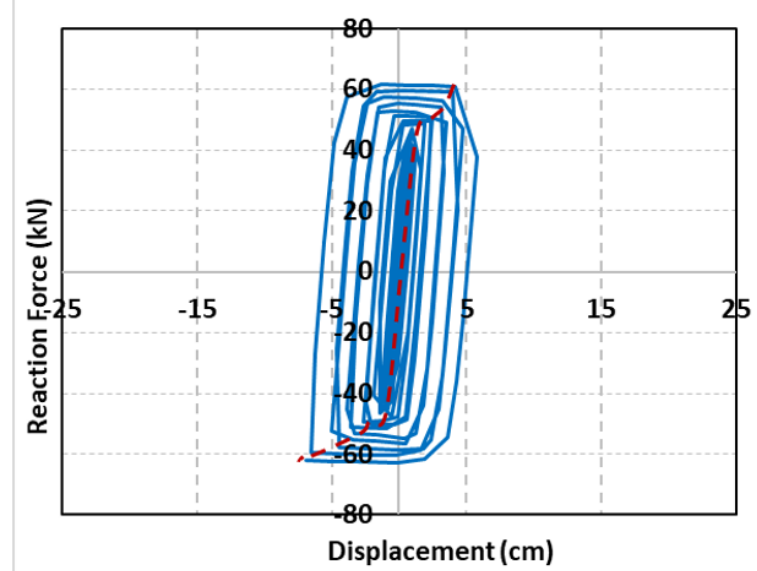

(a)

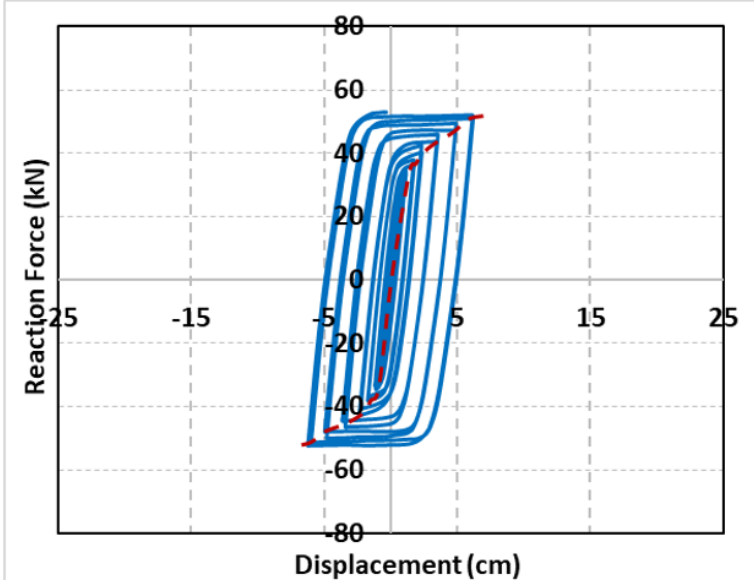

(b)

Figure 11: Reaction force versus displacement for 1st Floor (a) Model I and (b) Model II

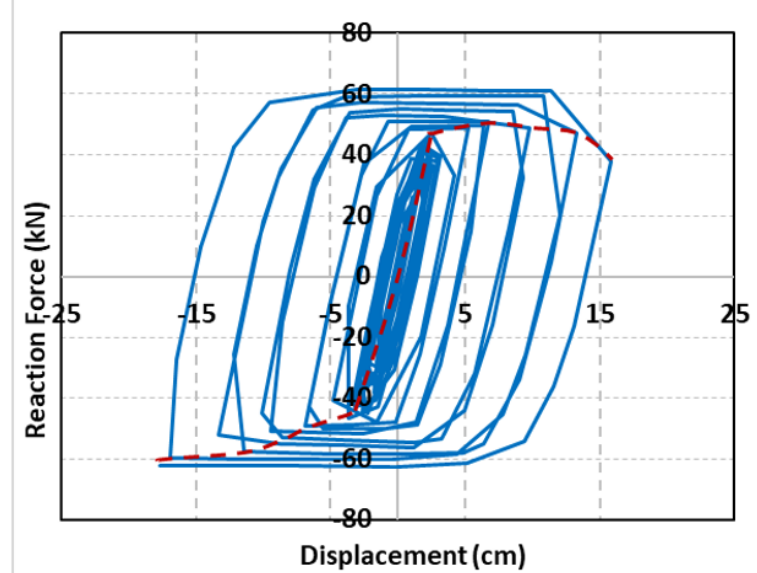

(a)

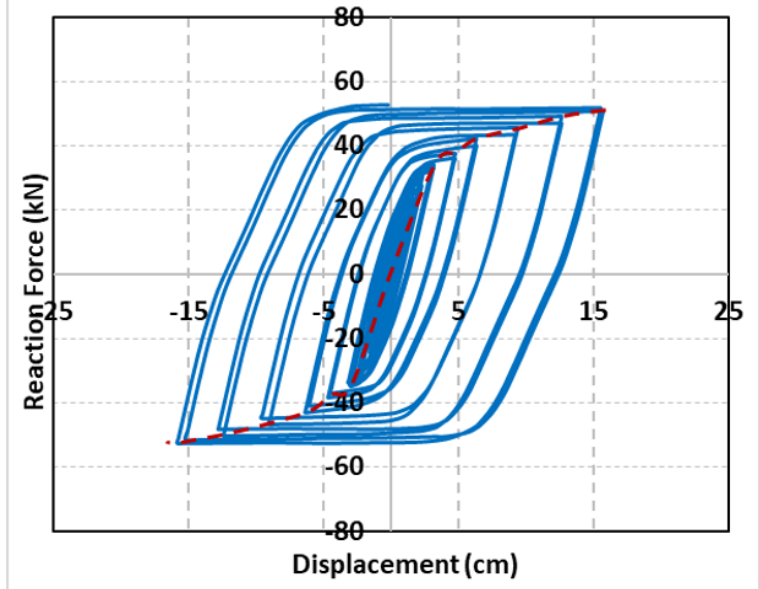

(b)

Figure 12: Reaction force versus displacement for 2nd Floor (a) Model I and (b) Model II

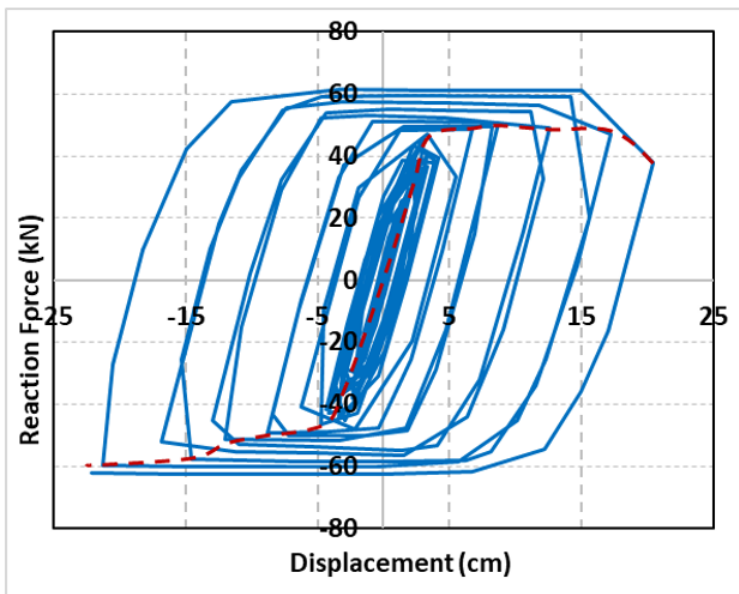

(a)

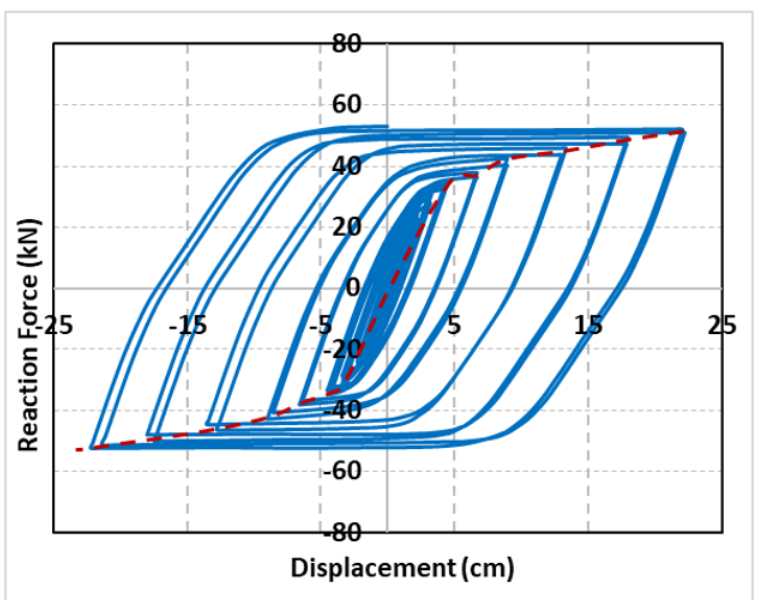

(b)

Figure 13: Reaction force versus displacement for 3rd Floor (a) Model I and (b) Model II

\section{SEISMIC FINITE ELEMENT MODELING}

A finite element model of the 3D cold-formed steel frame system test was modeled using ABAQUS commercial software as shown in Figure 14. Dividing the elements into a finite element mesh is one of the most important steps to 
converge the behavior of structure to reality. The analyzed models must have an extensive finite element mesh. However, the mesh of optimum finite elements must be determined as it will prolong the analysis time (Dubina.2008; Pouladi et al. 2019). Besides, the fine mesh is required at the joints in case of contact mechanics is defined in the interacting element, because these regions require a sensitive calculation and the presence of weak finite element networks in these regions may affect the analysis results as well as make the solution difficult; the analysis may be aborted and no results may be obtained.

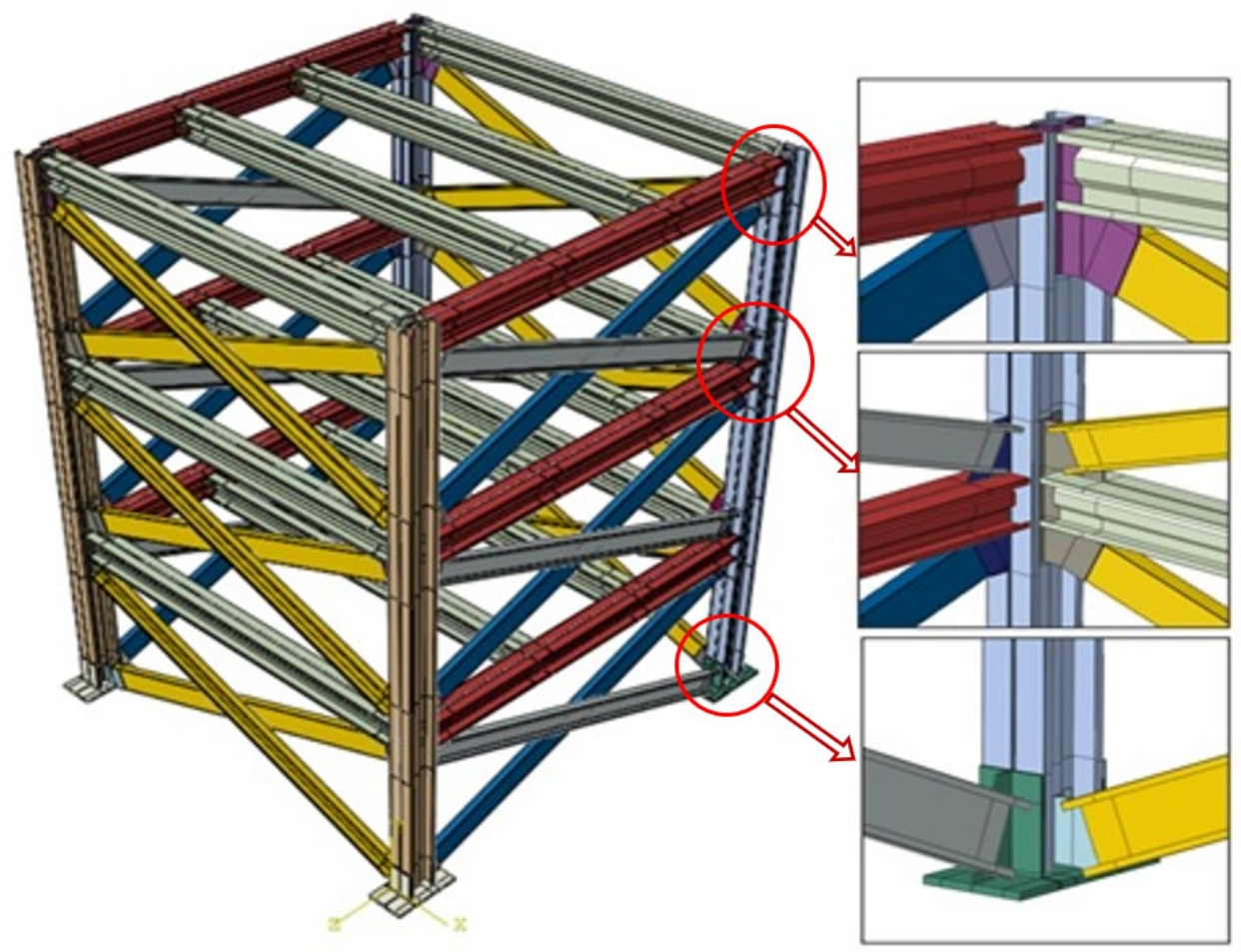

Figure 14: Finite element mesh of the CFS frame system

\subsection{Type of Elements and Finite Element Mesh}

The finite element mesh of the model was created. A coarse mesh was performed in the mid of the elements and in the regions that have no connected surfaces as shown in Figure 15. while a fine finite element mesh was created at the connected regions in the model to avoid the geometric discontinuities which may affect directly the accuracy of analysis results due to concentrating the stresses in these regions (Bučmys and Daniunas.2015; Schafer et al.2016). The C3D8R first-order linear reduced integration solid element type with 8 degrees of freedom for each node was chosen for all elements in the finite element model.
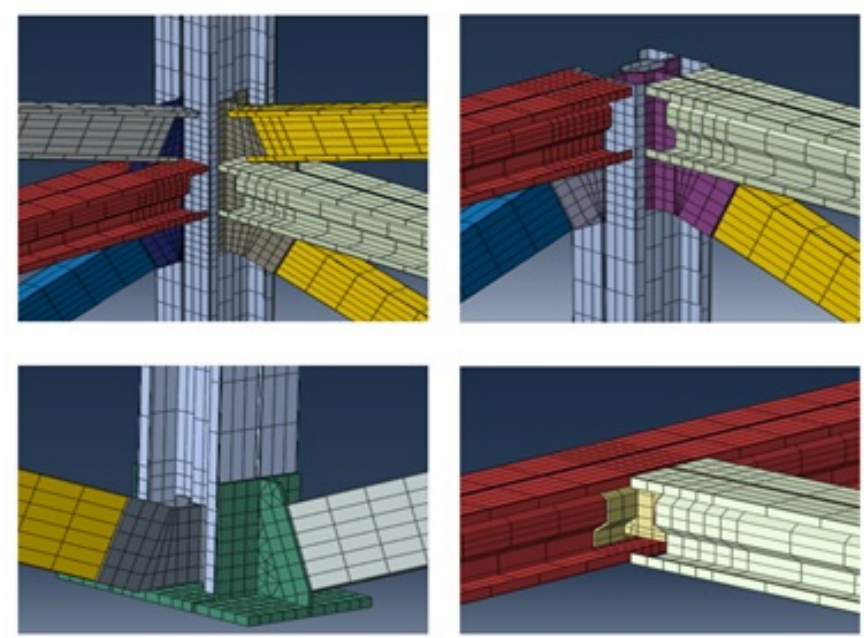

Figure 15: Finite element mesh of the CFS frame system 


\subsection{Modeling of connections}

Defining the interaction that occurs as a result of contact between the element surfaces directly affects the results of the analysis (Moushtakim, B. 2020; Feng and Young. 2015). In this study, since the structure is huge, some simplifications were made as much as possible in simulating the steel frame combination to provide multiplier solution time during the dynamic analysis. For example, in the real joints, a column-beam joint gusset plate $7 \mathrm{~mm}$ in thickness was used. The gusset plate connected the columns, beams, and braces by using M12 bolts. But in the finite element model, the connection regions between the gusset plates and the other members were defined as a full tie contact constraint, and the unconnected regions were defined as friction-less contact. This mechanism of simulation of surface connection may give results close as possible as to the reality. In the FE model, friction-less surface definitions were made including column-beam and gusset plate to braces surfaces for the joints in all directions of the model. Normal behavior and tangential behavior were defined in the contact surfaces to prevent them from sliding during the dynamic analysis as shown in Figure 16.

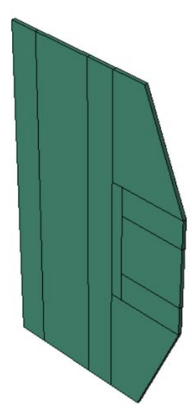

G.P in X-dir

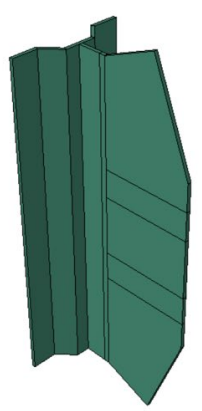

G.P in Y-dir
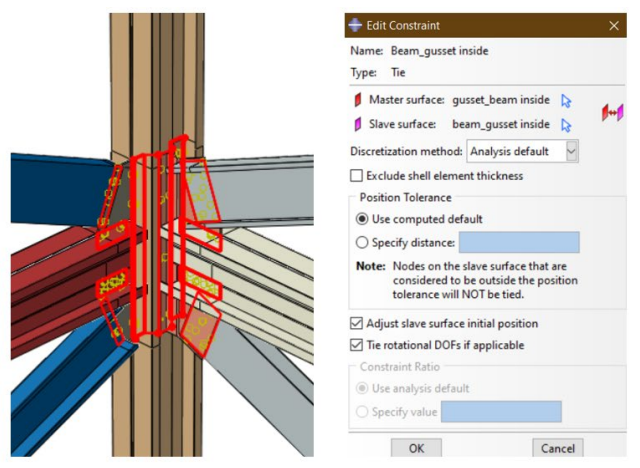

Figure 16: The full tie constraint used between the surfaces in the joints

The mechanism of the behavior of the connecting surfaces was observed in the cyclic FE analysis for the same model. However, it has been noticed that only the definition of surface-surface interaction is not sufficient as a result of the analysis. The results of cyclic FE analysis were shown that the elements are intertwined in the corner line surface interaction in the case of defining the contact surfaces of the bolts holes in reality. Therefore, in this analysis tie constraint was chosen at the connection joints in the ABAQUS software to avoid the local buckling and the intersection between the ends of the connected elements.

\subsection{Loading and boundary conditions}

Definitions such as material definitions, surface interactions, and boundary conditions were defined in the initial step in ABAQUS software. As a second step, the analysis was carried out under a static load on the steel frame. In static analysis, the general analysis was selected, while in dynamic analysis, the implicit dynamic analysis was chosen. The structure was loaded by static loads using the number of stone paves loaded on wooden plates which were supported by the flanges of the beams in the x-direction. The total weight of the stones loaded on each floor is approximately equal to $1400 \mathrm{~kg}$. In the finite element model, the loads were defined as a nonstructural mass applied on the beams in the $\mathrm{x}$ direction and every beam was loaded by $450 \mathrm{~kg}$. Loads were assigned along the beam section as distributed loads to minimize the local buckling which may occur on the flange of the beams during the dynamic analysis. Figure 17 shows the definition of static and dynamic loads in ABAQUS.
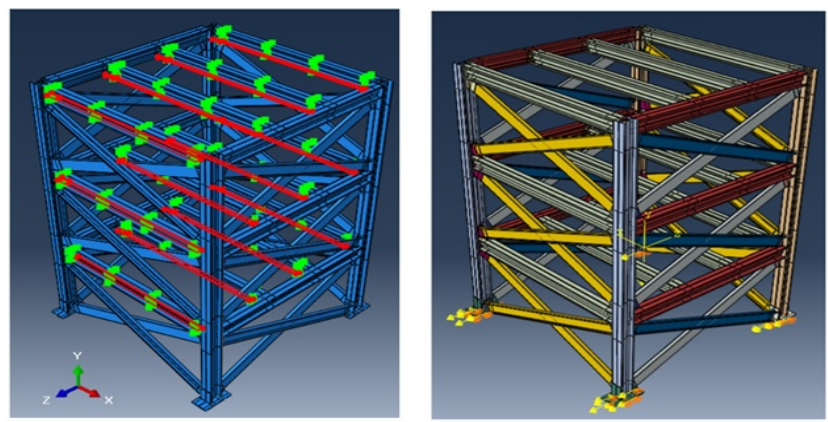

Figure 17: Static and dynamic loading on the structure 
In the static analysis, the supports were defined as fixed supports while in the dynamic analysis the boundary conditions were defined to allow the model to move in the z-direction by applying the earthquake acceleration records in this direction. A 3 degree of freedom was defined as 1 for the earthquake acceleration records to be applied on the supports of the structure in one direction.

The FE dynamic analysis of the structure was investigated using four input data of the ground motions; $50 \%$ scale and $100 \%$ scale of Northridge and Kocaeli earthquakes acceleration records. In each of them, the acceleration records were used in the analysis, and the amplitude of the acceleration applied to the supports as dynamic loads are shown in Figures 18 and 19. The dynamic implicit analysis was used in FE seismic analysis as mentioned previously. The dynamic parameters and seismic behavior of the structure under all input data were investigated during the FE analysis.

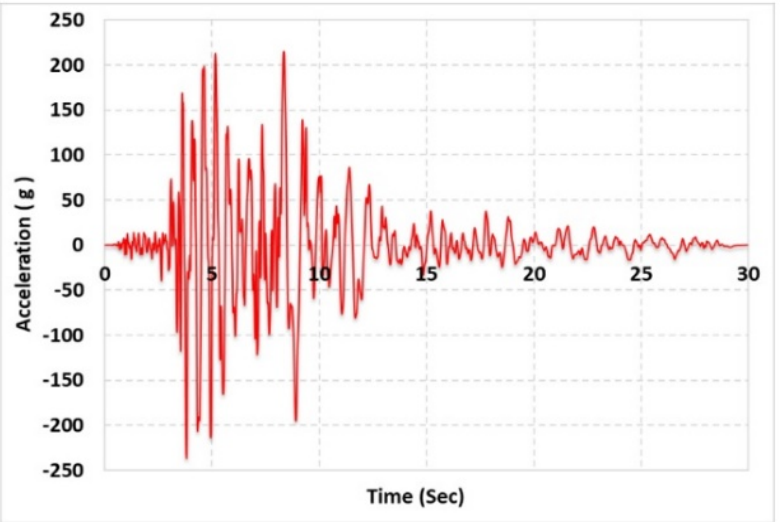

(a)

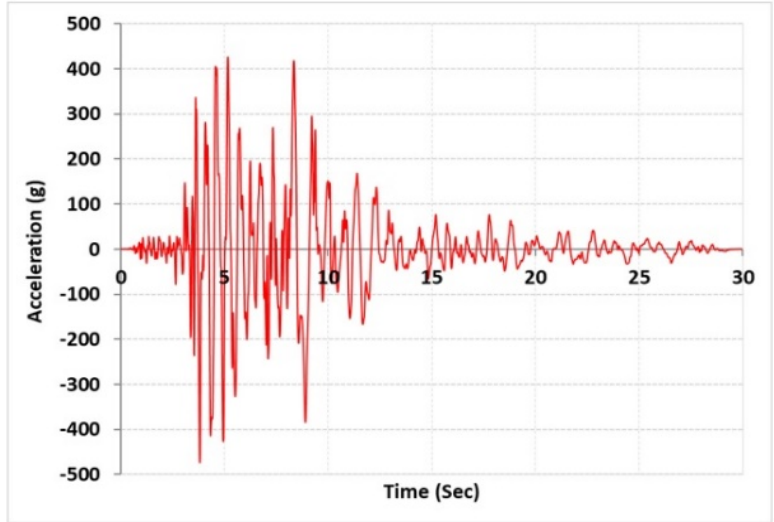

(b)

Figure 18: Acceleration records used in FE analysis a) $50 \%$ Scaled. b) $100 \%$ scaled of Northridge earthquake

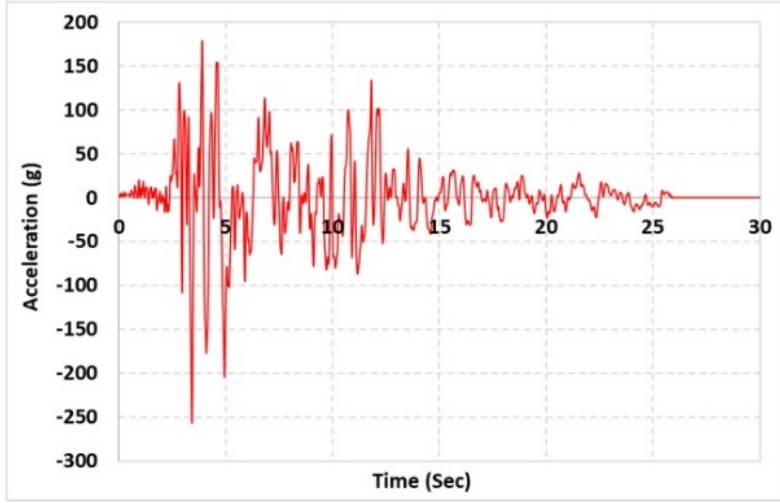

(a)

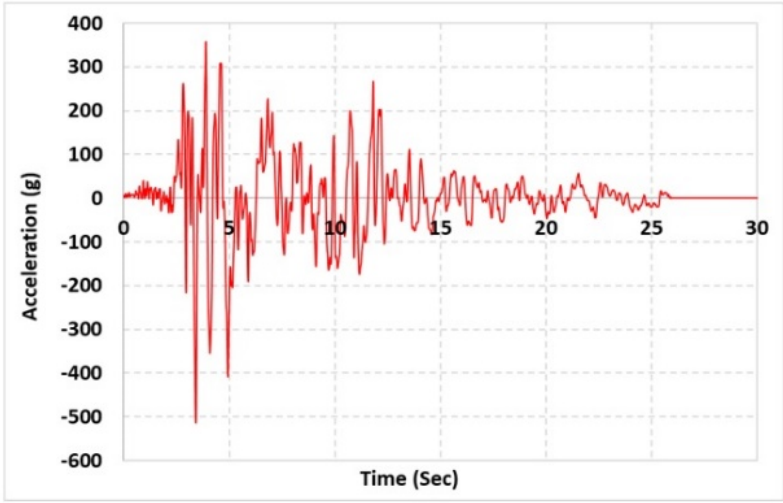

(b)

Figure 19: Acceleration records used in FE analysis a) $50 \%$ Scaled. b) $100 \%$ scaled of Kocaeli earthquake

\subsection{Finite Element Analysis Results}

The dynamic analysis was carried out using a consecutive input motion, $50 \%$ and $100 \%$, scales of Northridge and Kocaeli earthquake acceleration records with considering the hardening and nonlinear behavior of the members used to design the frame structure. The analysis could replicate adequately the responses of the analytical cases using the $50 \%$ and $100 \%$ scales of the Northridge and Kocaeli Earthquake.

The dynamic parameters were investigated during the finite element dynamic analysis. The maximum displacements at the same reference points specified on each floor in the structure were investigated during the dynamic analysis for each earthquake record. As well the maximum Von mises stresses during the analysis were observed at the left plates connected to the base with the brace in the z-direction at $4.714 \mathrm{sec}$ and these regions are still affected until $4.949 \mathrm{sec}$ of the earthquake time. After that, the maximum stress occurred at the top gusset plate connected to the mid beams to the beams in the z-direction as illustrated in Table 2.

Local buckling was observed at the gusset plate as shown in Figures 20 and 21 . When the displacement of the structure has reached the maximum at 8.87 seconds of the earthquake time, the distribution of Von stresses was highly 
concentrated at the upper connected joints in comparison with the middle joints; at the bottom of columns, and the braces close to the connection region. These concentrating stresses may relate to the number of connected members and the degree of freedom at these joints. The plastic strain concentration was observed at the top connection regions and the mid of secondary beams.

The braces on the first and second stories start demonstrating a small buckling in-lip parts of the braces $C$ sections at the regions close to the connection when the structure attains to the maximum displacements and that is related to the technique used to simulate the joins behavior. A local buckling also was observed mostly at the flange of the beams as a result of the applied static loading on the beams as shown in Figures 20 and 21.

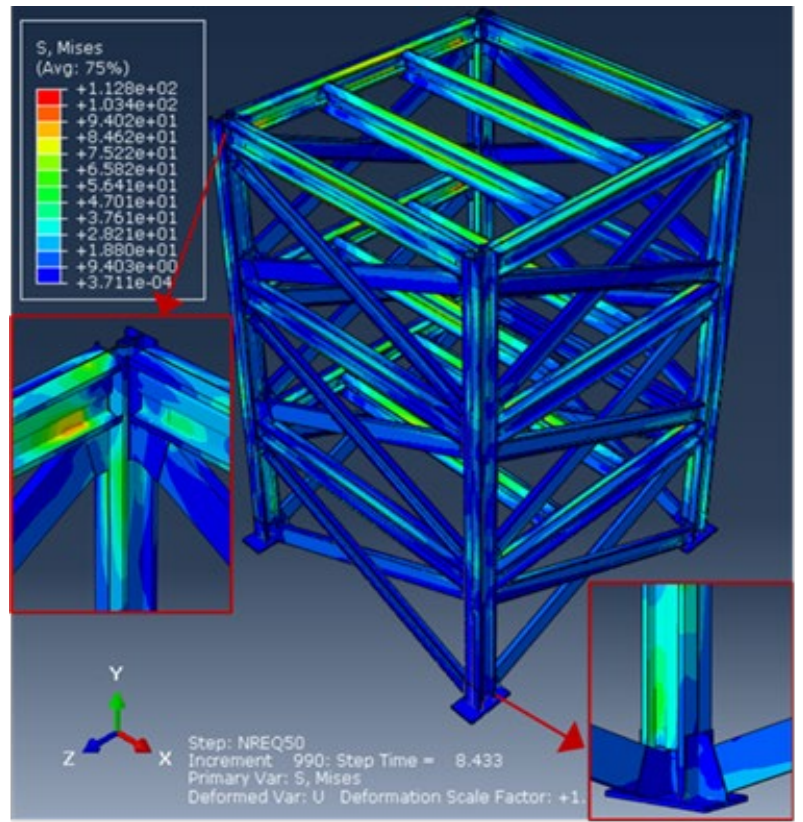

(a)

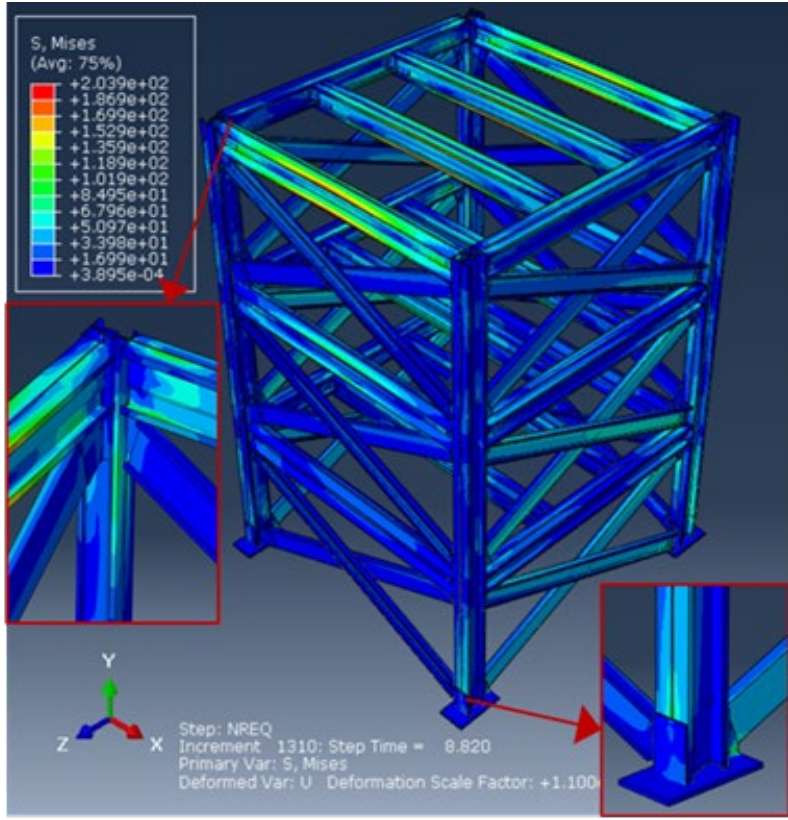

(b)

Figure 20: Von Mises stress distribution in the connections under (a) $50 \%$ and (b) $100 \%$ Northridge earthquake

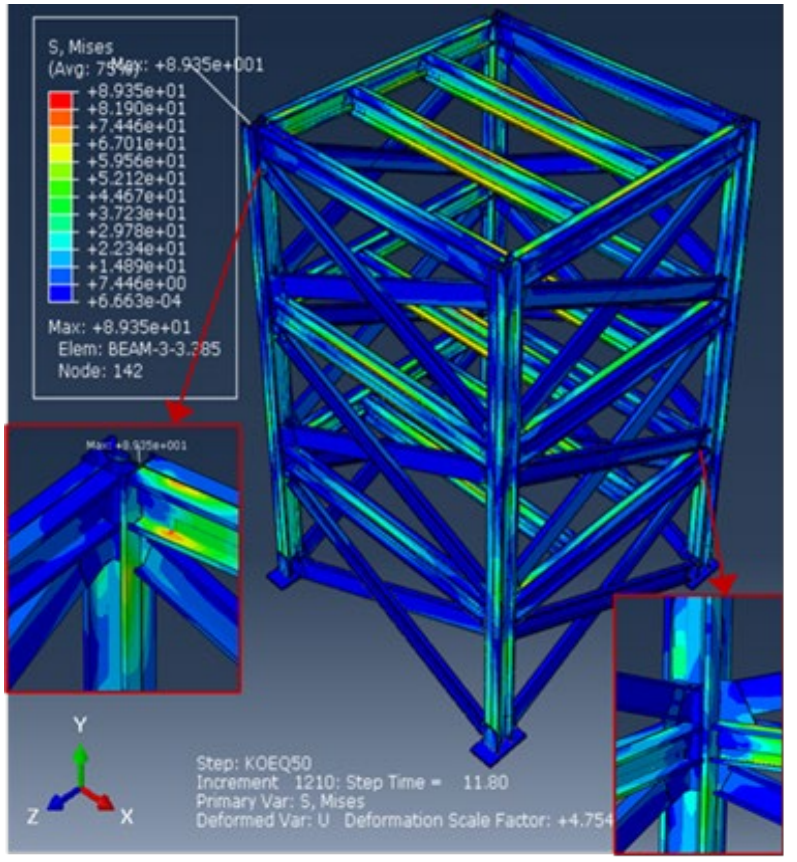

(a)

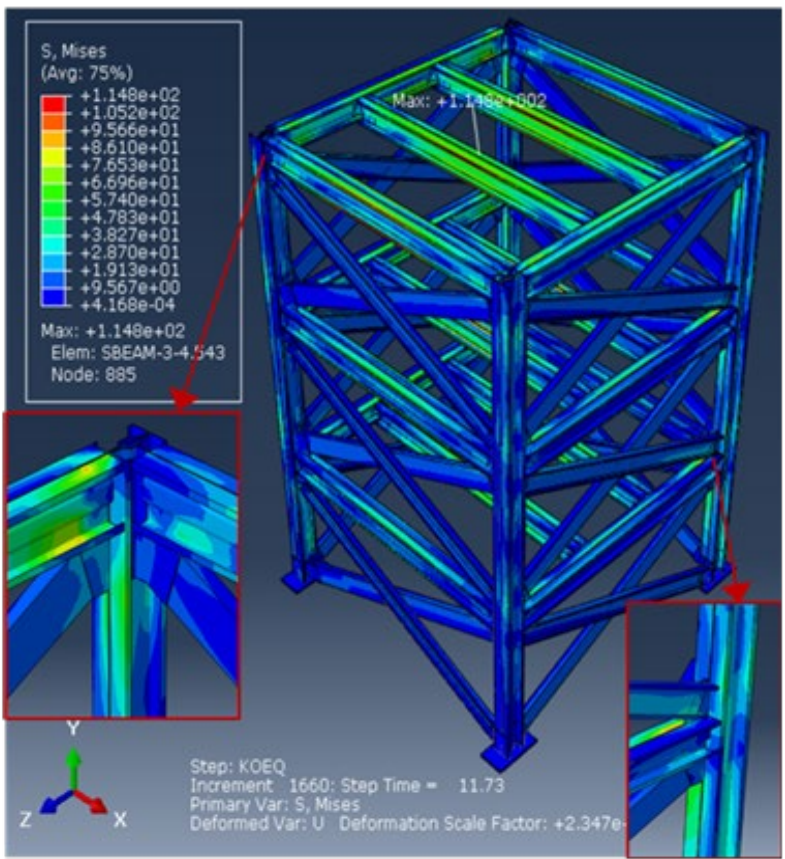

(b)

Figure 21: Von Mises stress distribution in the connections under (a) $50 \%$ and (b) $100 \%$ Kocaeli earthquakes 
The 3D steel CFS frame system has been modeled with the ABAQUS FE software, and the horizontal displacements at the points on the steel frame were compared with the data obtained by the image processing technique from the image records in the experiments for Northridge 50\%, Northridge 100\%, Kocaeli 50\%, and Kocaeli 100\% earthquakes. At the reference points in the steel frame model, only horizontal displacements were compared. However, according to the values taken from the video recording and numerical model, the modes of story drifts were the same but there were small differences. This may be because the selected material properties and the connection used in the beam-column joints are bolted connections, while in the numerical model, full constraint connection surfaces were defined in the joints. The low image resolution increases the error ratio in determining the amount of mm per pixel. For this reason, the difference between the numerical model and displacement values obtained from the recorded video increased.

\section{VALIDATION OF FINITE ELEMENT RESULTS}

The shaking table test results are discussed and compared with FE element analysis results. The maximum displacement in the cold-formed steel frame structure during the FE analysis was compared and discussed. As well, the maximum base shear force on the model resulted from the dynamic analysis with the different input data of the acceleration was investigated. The acceleration values for the system were observed during the FE analysis as shown in Figures 22 and 23.

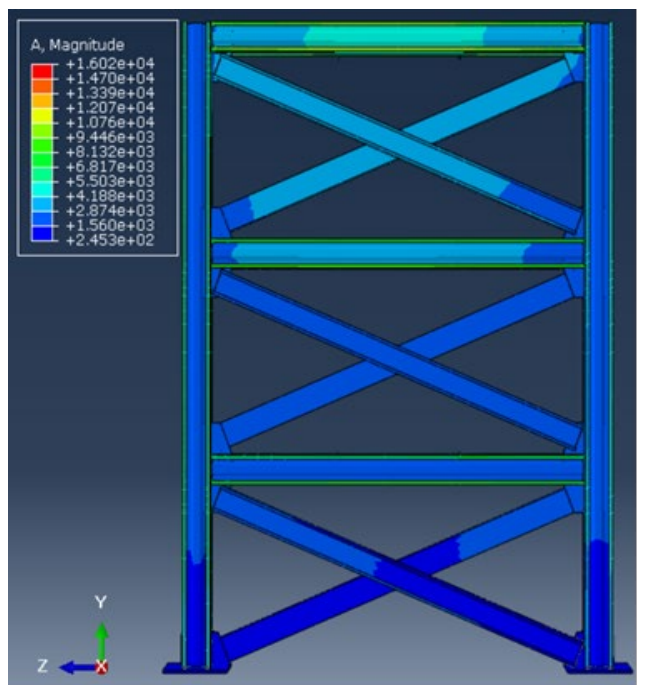

(a)

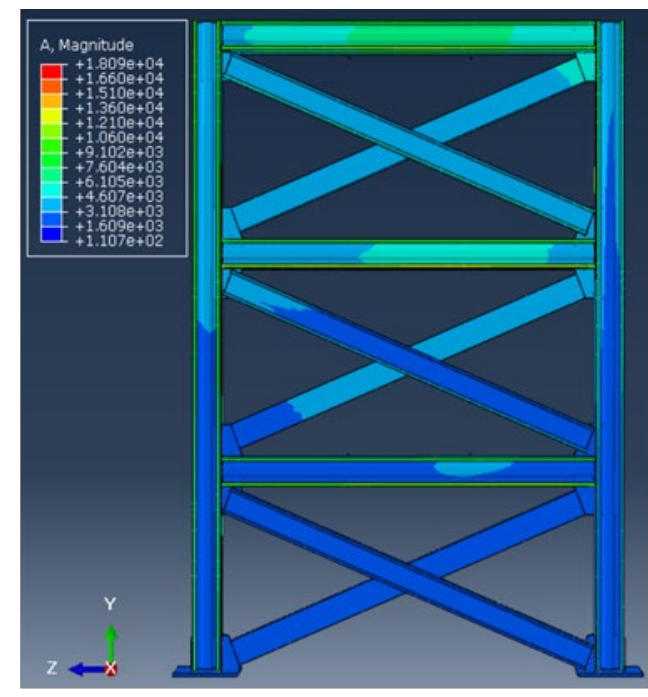

(b)

Figure 22: Acceleration value of system under (a) $50 \%$ and (b) $100 \%$ scales of Northridge earthquake records

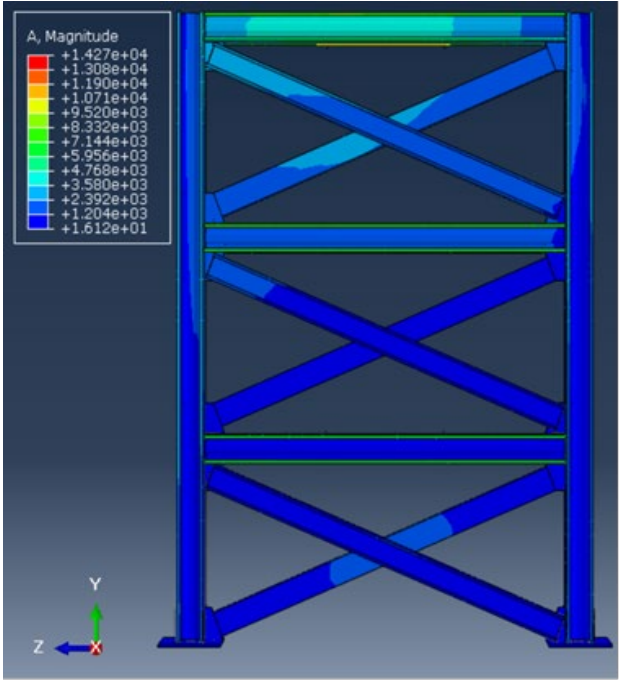

(a)

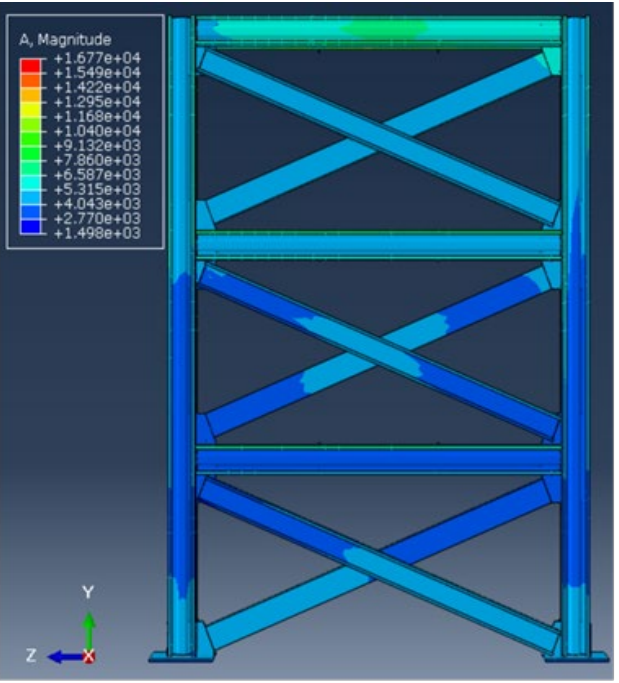

(b)

Figure 23: Acceleration value of system under (a) $50 \%$ and (b) $100 \%$ scales of Kocaeli earthquake records 
Table 2 Von Mises stress and strain obtained from FE analysis

\begin{tabular}{ccccc}
\hline Earthquake & \multicolumn{3}{c}{ Maximum Stress (Mpa) } & Maximum Strain \\
\hline Acceleration & Beams & Support & Joints & Plastic Strain \\
NR 100\% & 204 & 241 & 186.9 & 0.00262 \\
NR 50\% & 171.6 & 200 & 113 & 0.00056 \\
KO $100 \%$ & 230.8 & 215 & 112.3 & 0.00245 \\
KO 50\% & 181.9 & 198.9 & 90 & 0.00055 \\
\hline
\end{tabular}

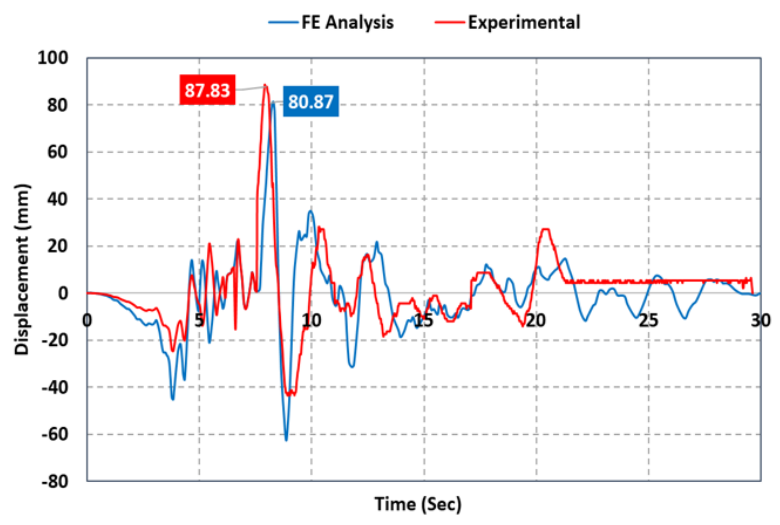

(a)

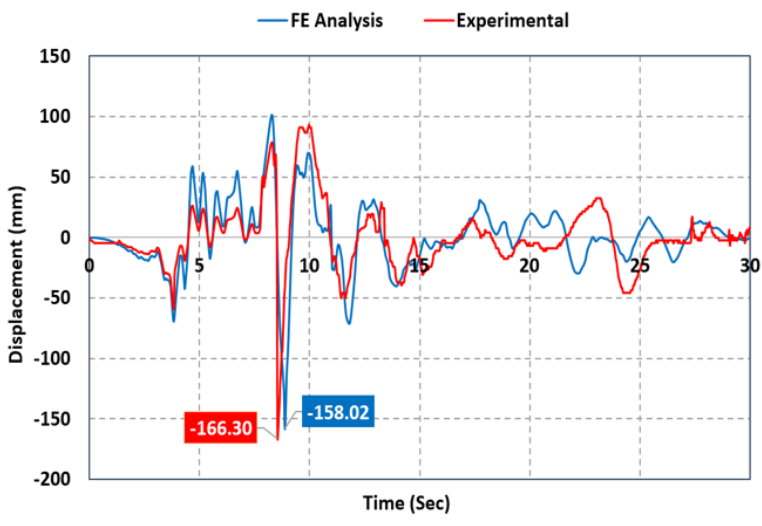

(b)

Figure 24: The maximum horizontal displacement in the top floor (a) $50 \%$ and (b) $100 \%$ scales of the Northridge earthquake

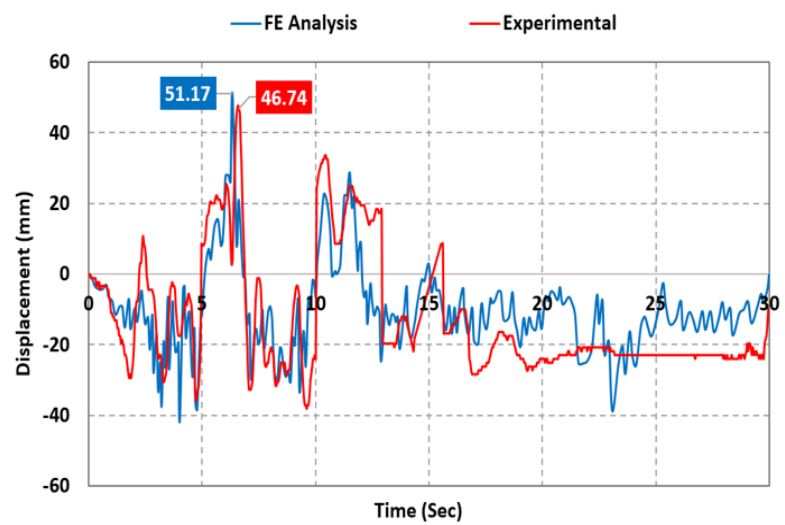

(a)

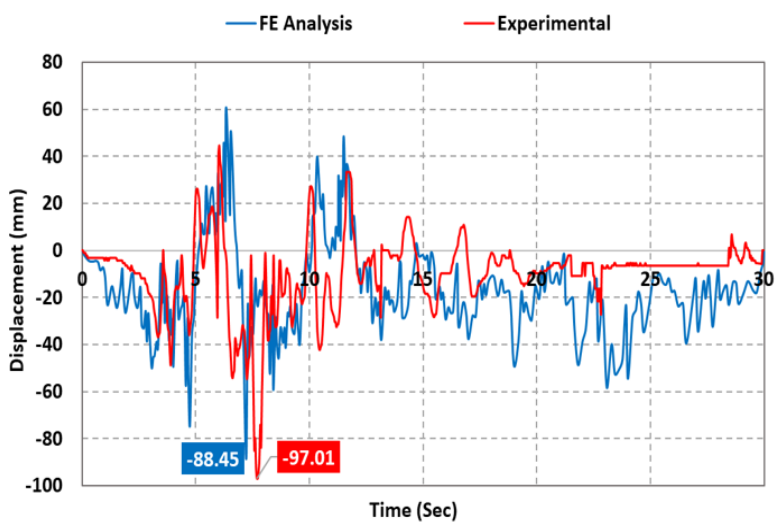

(b)

Figure 25: The maximum horizontal displacement in the top floor (a)50\% and (b)100\% scales of the Kocaeli earthquake

The displacement results of the structure obtained from the experimental test were compared with the FE results as shown in Figures 24 and 25. The graph of the deformation was obtained by subtracting the base displacement from the top displacement. To calculate the lateral whole stiffness of the steel frame system, the base shear force-deformation graph is presented in Figures 26 and 27. To calculate the floor stiffness, the shear force-relative floor displacement graph formed at the base of the column was drawn for each floor.

The results of the experimental test for the earthquake acceleration records were obtained. A comparison between the experimental and FE analysis displacement results was illustrated in Table 3 . It was shown that the results of the experimental test are approximately compatible with the results of FE analysis up to 20.13 seconds of earthquake time, after that the curve of displacement starts to differ as shown in Figures 24 and 25. The maximum displacements at the top floor of the structure were obtained from both FE element analysis and shaking table experimental test. 
Table 3 Maximum displacement in the structures $(\mathrm{cm})$

\begin{tabular}{ccccc}
\hline & \multicolumn{5}{l}{ Earthquake Acceleration Records } \\
\hline Result Type & NR 100\% & NR 50\% & KO 100\% & KO 50\% \\
FE analysis & 15.80 & 8.09 & 8.85 & 5.12 \\
Shaking table test & 16.63 & 8.78 & 9.70 & 4.67 \\
Difference \% & 5.12 & 8.18 & 9.16 & 9.19 \\
\hline
\end{tabular}

By comparing the maximum displacement values resulting from the FE analysis and the shaking table test, it was noted that the maximum difference percentages between the results were $5.12 \%, 8.18 \%, 9.16 \%$, and $9.19 \%$ for NR $100 \%$, NR 50\%, KO 100\%, and KO 50\% respectively, with an average similarity ratio of $92 \%$ between the FE and experimental results. These differences between the FE and experimental results were largely due to a simple movement was observed in the recording camera, which recorded the movement of the structure during the shaking table test. In addition to the way of defining the nonlinear behavior property of the cold-formed members and the mechanism of modeling the connections in the FE model.

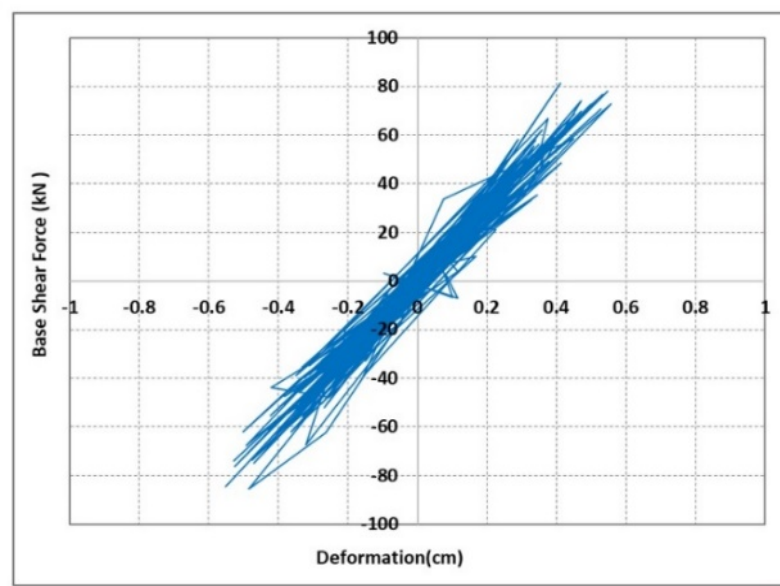

(a)

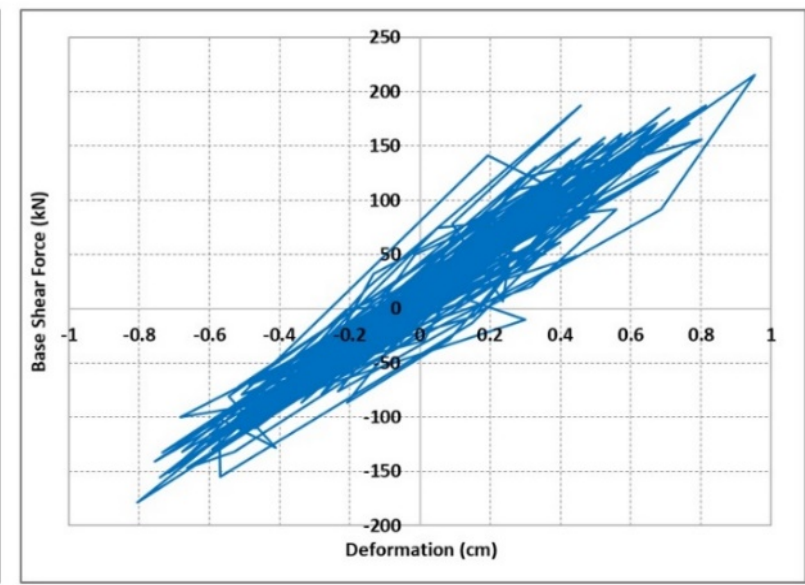

(b)

Figure 26: Base Shear-Displacement curves under (a)50\% and (b)100\% of Northridge earthquake

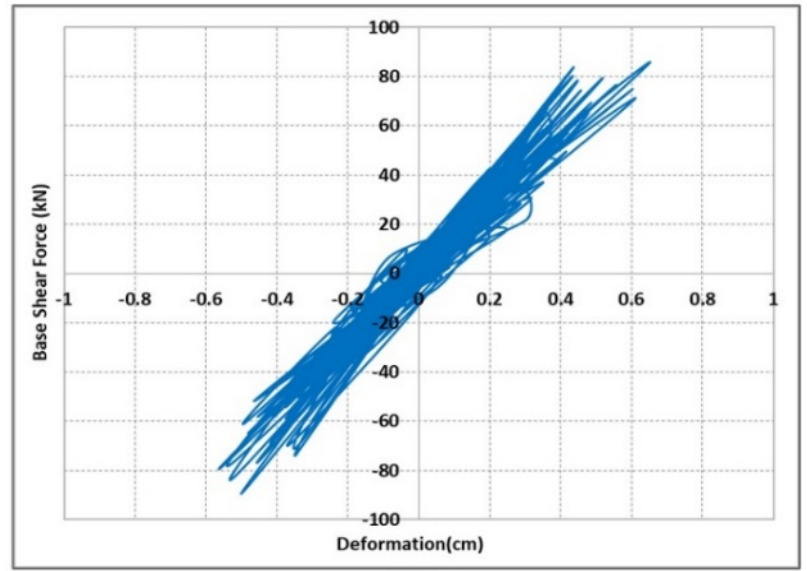

(a)

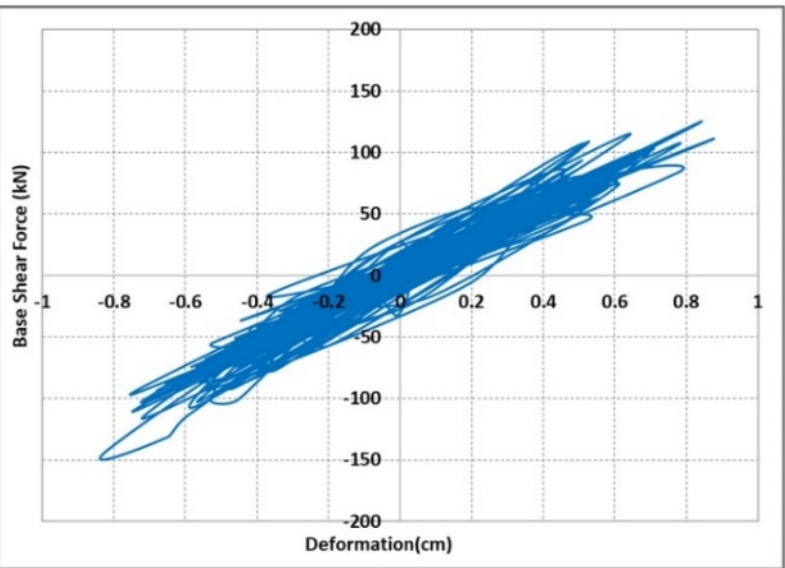

(b)

Figure 27: Base Shear-Displacement curves under (a)50\% and (b)100\% of Kocaeli earthquake

The translational stiffness of the structure was calculated as shown in Table 4. There are differences in the translational stiffness of the structure for each earthquake acceleration record. For example, by looking at the values obtained with Northridge $100 \%$ record, the floor stiffnesses are $900.92 \mathrm{kN} / \mathrm{cm}, 608.99 \mathrm{kN} / \mathrm{cm}$, and $584.13 \mathrm{kN} / \mathrm{cm}$ for the $1^{\text {st }}$ floor, $2^{\text {nd }}$ floor, and the $3^{\text {rd }}$ floor respectively. Floor stiffness decreases from the $1^{\text {st }}$ floor to the 3 rd floor. The system 
and floor stiffness resulted from all earthquake acceleration records have been normalized according to the Kocaeli $50 \%$ earthquake as shown in Table 5. The normalized values showed how the translational stiffness of the frame structure changes with different amplitudes and frequency values of the earthquakes.

Table 4 Translational stiffnesses capacity obtained from FE analysis $(\mathrm{kN} / \mathrm{cm})$

\begin{tabular}{ccccc}
\hline Earthquake & 1st Floor & 2nd Floor & 3rd Floor & Whole Structure \\
\hline KO 50\% & 683.87 & 405.72 & 338.43 & 144.23 \\
NR 50\% & 662.99 & 441.64 & 346.20 & 150.69 \\
KO 100\% & 723.78 & 429.27 & 383.19 & 157.74 \\
NR 100\% & 900.92 & 608.99 & 584.13 & 224.02 \\
\hline
\end{tabular}

The finite element analysis results showed that the lateral stiffness for the whole system, $1^{\text {st }}$, and $2^{\text {nd }}$ floors increases as the amplitude of the earthquake acceleration records decreases while the $3^{\text {rd }}$ floor stiffness decreases most during the Kocaeli $50 \%$ earthquake. The lateral stiffness of the $1^{\text {st }}$ floor most decreased during Northridge $50 \%$ earthquake.

Table 5 Normalized values of the translational stiffnesses results

\begin{tabular}{ccccc}
\hline Earthquake & 1st Floor & 2nd Floor & 3rd Floor & Whole Structure \\
\hline KO 50\% & 1.000 & 1.000 & 1.000 & 1.000 \\
NR 50\% & 0.969 & 1.089 & 1.023 & 1.045 \\
KO 100\% & 1.058 & 1.058 & 1.132 & 1.094 \\
NR 100\% & 1.317 & 1.501 & 1.726 & 1.553 \\
\hline
\end{tabular}

\section{CONCLUSIONS}

The seismic behaviour parameters were observed during the experimental and numerical FE analysis. The results of finite element dynamic analysis showed that the cold-formed steel frame structure demonstrated an adequate lateral strength capacity for all input data and the behavior of the structure reached the plastic regions when $100 \%$ scale of Northridge and Kocaeli earthquake records are used. Furthermore, the results showed that the maximum displacement on the frame structure is $15.80 \mathrm{~cm}$ for $100 \%$ scale of Northridge earthquake acceleration records while the maximum displacement is $8.85 \mathrm{~cm}$ for $100 \%$ scale of Kocaeli earthquake acceleration records.

The conclusions below were established based on both FE analysis and experimental test:

From the cyclic analysis, it can be concluded that the cyclic behavior of the steel frame is governed by the bracing system and the mechanism of failure is controlled by the types and stiffness of connections that use in the joints.

The results of FE analysis under cyclic loading revealed that the braces in all stories of the CFS frame exhibited similar stress distribution when the connection on the frame was simulated as a bolt shank area. While, in the case of the simulation of the connected region as full constraint surfaces, the stress distribution on the braces widely differed from one story to another as a result of the transition mechanism for the stress among the elements forming the structure.

It was concluded that simulation of the connected regions as full tie constraint caused the accumulation of the lateral displacement in the second story of the frame as a result of the soft story formation and this followed with significant buckling of the braces.

The results of finite element analysis under cyclic loading proved that the mechanism of bolts simulation as full tie constraint contact at the connection region makes the converge of analysis so easy and gives results close somewhat to the reality.

In the cold-formed steel structures, it is proposed to use stiffeners in the mid of beams to reduce the effective length as possible to minimize the buckling.

The results of the FE analysis showed that the stress concentrations in the gusset plates located in the Z-direction are smaller than the stress generated at the beams at the same location.

According to the experimental and FE analysis results, it can be concluded that the thickness of the gusset plate used plays a major role in the stress distributions at the joints and braces in the cold-formed steel frame structures. 
During shaking table testing, it was concluded that the calibration of the test on the shaking table and the distance between the tested structure and the camera used to record the movement of the structure during the shaking table test mainly affect the accuracy of the results.

The numerical FE analysis and experimental test results exhibited acceptable agreement. Although, one apparent difference between the displacement results related to the connection behaviour which is modeled using a connector element to simulate the actual mechanical property of a bolt bearing against the gusset plate.

The results of this study and previous studies showed that as the resolution and speed of the video recording camera during the shaking table experiment increases, the results obtained become clearer.

In the shaking table experiment when a full-scale experimental sample is used, it may be required to obtain dynamic parameters at many points on the structure. Placement of the measuring instruments on the sample, the precision of the measurements, and the excess of the measured points increase the cost of obtaining these dynamic parameters.

This study and many previous studies have been shown that using the image processing technique in the experimental shaking table test can be offered much more acceptable and economical solutions in determining the displacement parameters in comparison with the other methods.

\section{ACKNOWLEDGMENTS}

Part of this work is the special cold-formed steel profiles, which were supported by Istanbul Development Agency, Project No. TR10/15/YNK/0034. The supports are gratefully acknowledged.

Author's Contributions:Conceptualization, F Alemdar and FMA AL-GAADI; Methodology, F Alemdar and FMA AL-GAADI; Investigation, F Alemdar and FMA AL-GAADI; Software, FMA AL-GAADI and F Alemdar; Writing - original draft, FMA ALGAADI; Writing - review \& editing, F Alemdar; Validation, FMA AL-GAADI and F Alemdar; Resources, FMA AL-GAADI and F Alemdar; Supervision, F Alemdar.

Editor: Marco L. Bittencourt

\section{References}

Sabbagh, B. A. et al. (2012) 'Experimental work on cold-formed steel elements for earthquake resilient moment frame buildings', Engineering Structures, 42: 371-386. doi: 10.1016/j.engstruct.2012.04.025.

Ye, J., Mojtabaei, S. M., Hajirasouliha, I. and Pilakoutas, K. (2019) 'Efficient design of cold-formed steel bolted-moment connections for earthquake resistant frames', Thin-Walled Structures, 150.doi: 10.1016/j.tws.2018.12.015.

Aly, E.H.A.H. et al. (2018) 'Strength and Ductility of Steel Cold-Formed Section Beam to Column Bolted Connections', International Congress and Exhibition Sustainable Civil Infrastructures, 431-445. doi:10.1007/978-3-319-61914-9_33.

Bučmys, Ž., and Daniunas, A. (2015) 'Analytical and experimental investigation of cold-formed steel beam-to-column bolted gusset-plate joints', Journal of Civil Engineering and Management, 21:1061-1069. doi:10.3846/13923730.2015.1084039

Wrzesien, A., Lim, J. B. P., Nethercot, D. A. (2012) 'Optimum Joint Detail for a General Cold-Formed Steel Portal Frame', Advances in Structural Engineering, 15(9): 1623-1639. doi: 10.1260/1369-4332.15.9.1623

Schafer, B.W. et al. (2016) 'Seismic response and engineering of cold-formed steel framed buildings', Structures, 8. doi: 10.1016/j.istruc.2016.05.009

Dubina, D. (2008) 'Behavior and performance of cold-formed steel-framed houses under seismic action', Journal of Constructional Steel Research, 64(7): 896-913. doi: 10.1016/J.JCSR.2008.01.029.

Di Lorenzo, G and Martino, A. (2019) 'Earthquake Response of Cold-Formed Steel-Based Building Systems: An Overview of the Current State of the Art', Buildings, 9. 228. doi:10.3390/buildings9110228.

Fiorino, L., luorio, O., Landolfo, R. (2014) 'Designing CFS structures: The new school bfs in naples', Thin-Walled Structures, 78: 37-47. doi: 10.1016/J.TWS.2013.12.008.

Pouladi, P. et al. (2019) 'Finite-element assisted design of eaves joint of cold-formed steel portal frames having single channelsections', Structures, 29. 452-464. doi: 10.1016/j.istruc.2019.05.009. 
Amin, I., Ali, A. A., and Mohamad, N. N. (2019) 'Evaluation of cyclic behaviour of special concentrically braced frames with built-up diagonal braces', Australian Journal of Structural Engineering, 20(1): 10-25.doi: 10.1080/13287982.2018.1551847.

McCrum, D.P. et al. (2018) 'Experimental cyclic performance of cold-formed steel bolted moment resisting frames', Engineering Structures, 181. doi: 10.1016/j.engstruct.2018.11.063.

Moushtakim, B. (2020). Evaluation of Response Modification Factor for Different Types of Stainless-Steel Frames. Bangladesh University of Engineering and Technology. Master's thesis.

Bosco, M., Ghersi, A., Marino, E.M., \& Rossi, P.P. (2013) 'Prediction of the Seismic Response of Steel Frames with Concentric Diagonal Bracings', The Open Construction and Building Technology Journal, 7, 118-128. doi:10.2174/1874836820130911003.

Nip, A., Gardner, L. and Elghazouli, A. (2013) 'Ultimate behaviour of steel braces under cyclic loading', Proceedings of the ICE Structures and Buildings. doi: 166.219-234.10.1680/stbu.11.00028.

Faytarouni, M., Shen, J., Akbas, B. (2019) 'Evaluation of brace fracture models in seismic analysis of concentrically braced frames. Journal of Constructional Steel Research. 162, 1-17. doi: 10.1016/j.jcsr.2019.105709.

Tremblay, R. (2002) 'Inelastic seismic response of steel bracing members', Journal of Constructional Steel Research, 58: 665701. doi:10.1016/S0143-974X(01)00104-3.

Feng, R., Young, B. (2015) 'Theoretical analysis of cold-formed stainless steel tubular joints', Engineering Structures, 83, 99115. doi: $10.1016 /$ j.engstruct.2014.10.030

Krawinkler, H., Seneviratna, G.D. (1998) 'Pros and cons of a pushover analysis of seismic performance evaluation', Engineering Structures, 20:452-464. doi:10.1016/S0141-0296(97)00092-8.

Vahdani, R., Gerami, M., and Razi, M. (2017) 'Seismic Vulnerability Assessment of Steel Moment-Resisting Frames Based on Local Damage', Journal of Earthquake and Tsunami,11. 1750016. doi:10.1142/S1793431117500166.

Avcl, N., Alemdar, F. (2019) 'Shaking table test and numerical simulation of 3D steel frame system', Journal of Structural Engineering and Applied Mechanics, 2(2):88-95. doi:10.31462/JSEAM.2019.02088095.

Goggins, J. et al. (2017) 'Shake table testing of concentrically braced steel structures with realistic connection details subjected to earthquakes', Structures, 13. doi: 10.1016/j.istruc.2017.12.003.

Campiche, A. (2020) 'Numerical modelling of CFS three-story strap-braced building under shaking-table excitations', Materials, 14. 118. doi:10.3390/ma14010118.

Firouzianhaij, A., Usefi, N., Samali, B., and Mehrabi, P. (2021) 'Shake table testing of standard cold-formed steel storage rack', Applied Sciences, 11. 1821. doi:10.3390/app11041821.

Alemdar, F., Geleta, H., Algaadi, F. (2021) 'Moment-rotation characteristics and finite element analysis of cold-formed steel connections', Uludag University Journal of The Faculty of Engineering, 26: 29 - 46. doi: 10.17482/uumfd.798136. 